\title{
El valor de la declaración de las partes en el proceso de nulidad
}

\section{The Value of the Declaration of Parties in the Nullity Process}

\author{
José Tomás MARTín DE AgAR \\ Profesor Ordinario \\ Pontificia Università della Santa Croce. Facoltà di Diritto Canonico. Roma \\ martinagar@pusc.it
}

Resumen: Se estudian los principales tipos de declaración judicial de las partes (confesiones y declaraciones) desde dos puntos de vista complementarios: a) su valor legal como medio de prueba; b) su relevancia para la adquisición de la verdad de los hechos por parte del juez. Bajo el primer aspecto se propone el cuadro de la evolución normativa y conceptual desde el CIC de 1917 hasta el MP Mitis ludex (2015), señalando los pasos de la creciente estimación normativa de esas declaraciones como medio de prueba. El segundo aspecto, de su importancia para el conocimiento efectivo de lo acontecido, se trata en el contexto del nuevo processus brevior instituido en el citado Motu proprio, del cual se ilustran los rasgos principales. Se termina poniendo en relación la declaración de las partes con cada una de las circunstancias «que pueden permitir tratar la causa... a través del proceso más breve» mencionadas en la Ratio procedendi (art. 14 \$1) del Motu proprio.

Palabras clave: Mitis Iudex, Causas de nulidad, Proceso matrimonial, Instrucción, Prueba, Confesión judicial, Declaración de las partes, Processus brevior.
Abstract: This article addresses the main types of declarations by parties (judicial confessions and declarations), considering them from two complementary points of view: a) their legal status as a form of proof; and b) their significance in the process whereby the judge ascertains the truth of the facts. Regarding the first point, a framework of normative and conceptual evolution from the 1917 CIC to MP Mitis ludex (2015) is outlined, noting the increasing normative value of such declarations as a form of proof. Given its relevance to an effective understanding of this development, the second point is addressed in the context of the new processus brevior instituted in the aforementioned Motu Proprio, describing its main features. The article concludes by considering the declaration of parties in relation to each of the circumstances «that can allow a case ... to be handled by means of the briefer process», mentioned in the Ratio procedendi (art. 14 \$1) of the Motu proprio.

Keywords: Mitis ludex, Marriage Nullity Cases, Marriage Process, Instruction, Proof, Judicial Confession, Declaration of Parties, Processus brevior. 


\section{INTRODUCCIÓN}

E n su discurso a la Rota del año 2016 el Papa decía a los jueces que «cuando la Iglesia, a través de vuestro servicio, se propone declarar la verdad sobre el matrimonio en el caso concreto, para el bien de los fieles, al mismo tiempo tiene siempre presente que quienes, por libre elección o por infelices circunstancias de la vida ${ }^{1}$, viven en un estado objetivo de error, siguen siendo objeto del amor misericordioso de Cristo y por lo tanto de la misma Iglesia».

Verdad y misericordia son inseparables, no alternativas: se distinguen y se implican mutuamente. Aclarar y declarar la verdad sobre los matrimonios fallidos, y por consiguiente sobre el remedio que puede caber en cada situación, es de por sí una obra de misericordia. Me gusta que el Papa Francisco haya indicado la verdad como objeto propio e inmediato del ministerio judicial, como dando a entender que fundamento y justificación de toda decisión es antes que nada el esclarecimiento de los hechos sobre los que recae. Por decirlo brevemente: el razonamiento in iure más elaborado y profundo será convincente en cuanto se proyecte sobre hechos que puedan razonablemente considerarse históricos, o sea sucedidos in casu.

De aquí la relevancia de la instrucción de la causa ${ }^{2}$.

Ésta es una investigación reglada en la que el instructor, dentro de los medios y facultades que le ofrece la ley, procura averiguar los hechos relevantes para la solución del problema jurídico planteado. Los resultados son siempre un conjunto de datos, más o menos comprobados, entramados entre sí, que constituyen el caso. Sólo teóricamente se puede imaginar un proceso cuya instrucción dé como resultado, por decir así, sólo un hilo y no un tejido.

\footnotetext{
1 «Quizás todo este flagelo tiene un nombre extremadamente genérico, pero en este caso trágicamente verdadero, y es egoísmo. Si el egoísmo gobierna el reino del amor humano, que es precisamente la familia, lo envilece, lo entristece, lo disuelve. El arte de amar no es tan fácil como comúnmente se cree. No basta el instinto para enseñarlo. La pasión mucho menos. El placer tampoco» (G. B. MonTini, Carta pastoral a la archidiócesis ambrosiana al comienzo de la Cuaresma de 1960). [Nota del original].

2 «L'esito dell'istanza non dipende dalla ragionevolezza delle argomentazioni addotte quanto soprattutto dalla efficacia e stringenza delle allegazioni probatorie» (M. DEL Pozzo, Il processo matrimoniale più breve davanti al Vescovo, Edusc, Roma 2016, 169).
} 
Y aquí entra el tema que se me ha asignado dentro del conjunto de este Simposio: el valor procesal de la declaración de las partes, tema que consideraré en dos aspectos en realidad inseparables:

- el valor probatorio que según la ley puede el juez atribuirle;

- su importancia instructoria en orden al conocimiento de los hechos sobre los que debe recaer la decisión ${ }^{3}$.

Cualquier reflexión sobre las pruebas, su función y su apreciación por el juez, ha de estar iluminada y matizada por los principios que rigen esta actividad al menos en las causas de nulidad de matrimonio: el de libre valoración de las pruebas y el de certeza moral (c. 1869 CIC17, c. 1608 CIC). Están íntimamente imbricados de manera que simul stabunt et simul cadebunt. Son también expresión de la independencia del juez, no de la ley sino en la aplicación de la ley al caso ${ }^{4}$.

\section{EVOLUCIÓN NORMATIVA DEL VALOR PROBATORIO DE LA DECLARACIÓN DE LAS PARTES}

Como para cualquier otro medio de prueba, el valor judicial de la declaración de las partes, quiere decir el valor que según la ley el juez puede atribuirle, no que deba. La ley puede -y sólo hasta cierto punto- limitar ese valor, pero no imponerlo (salvo en casos de objetiva evidencia); hay una dimensión subjetiva en la valoración judicial de las pruebas que de algún modo las sitúa fuera de cualquier tasación legal.

En este marco, las declaraciones de las partes han adquirido, en general y en las causas de nulidad, una mayor relevancia y peso que en el pasado, evolución normativa que ilustra esquemáticamente ${ }^{5}$ el siguiente cuadro comparativo:

\footnotetext{
3 Vid. M. J. ARRoba Conde, Relación entre las pruebas y la comprobación de la verdad en el proceso canónico, Anuario de Derecho Canónico 1 (abril 2012) 11-36; P. BIANCHI, Il servizio alla verità nel processo matrimoniale, Ius Canonicum 57 (2017) 83-104.

4 Mantiene toda su actualidad sobre este tema el Discurso de Pío XII a la Rota de 1942, en especial nn. 3-5: AAS 34 (1942) 338-343, también en btcaah.

${ }^{5}$ Para una exposición detallada del origen e iter de estos textos que presentamos, J. LLOBELL, La genesi dei disposti normativi sul valore probatorio delle dichiarazioni delle parti: il raggiungimento del principio della libera valutazione delle prove, en S. GHERRO (cur.), Confessione e dichiarazione delle parti nelle cause canoniche di nullità matrimoniale, Padova 2003, 99-145 (también en btcaev); A. RIPA, La novità mancata, Lateran University Press, Città del Vaticano 2010.
} 


\begin{tabular}{|c|c|c|}
\hline 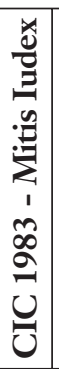 & 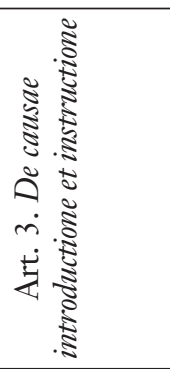 & \\
\hline 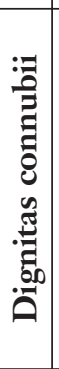 & 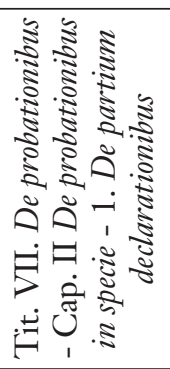 & 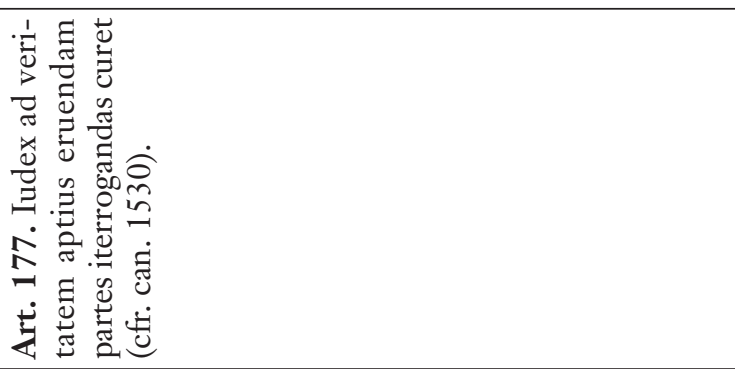 \\
\hline 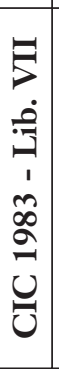 & 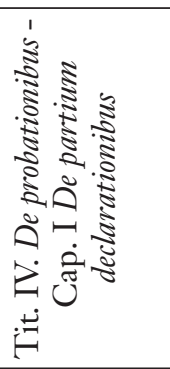 & 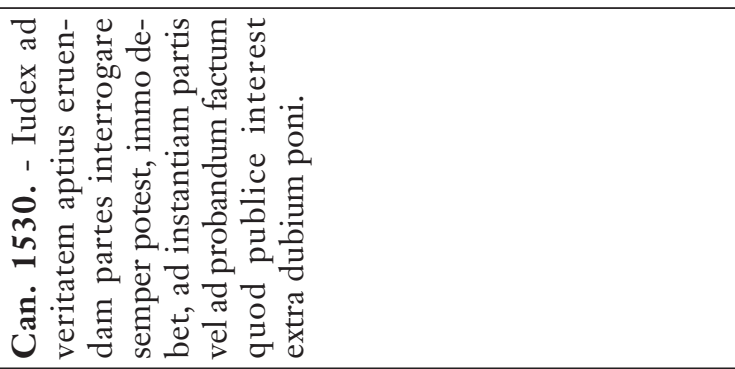 \\
\hline 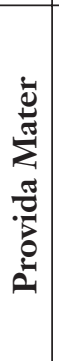 & 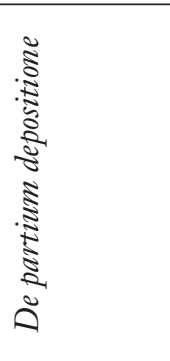 & 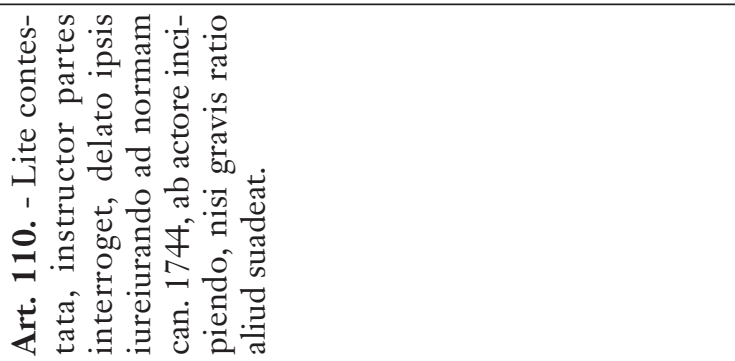 \\
\hline 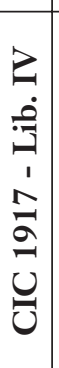 & 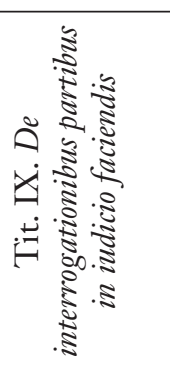 & 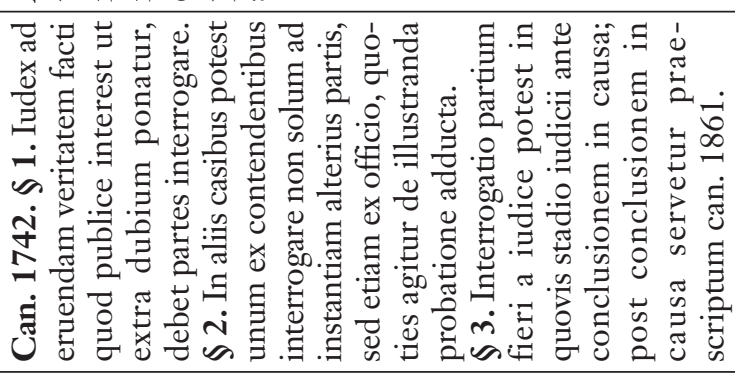 \\
\hline
\end{tabular}




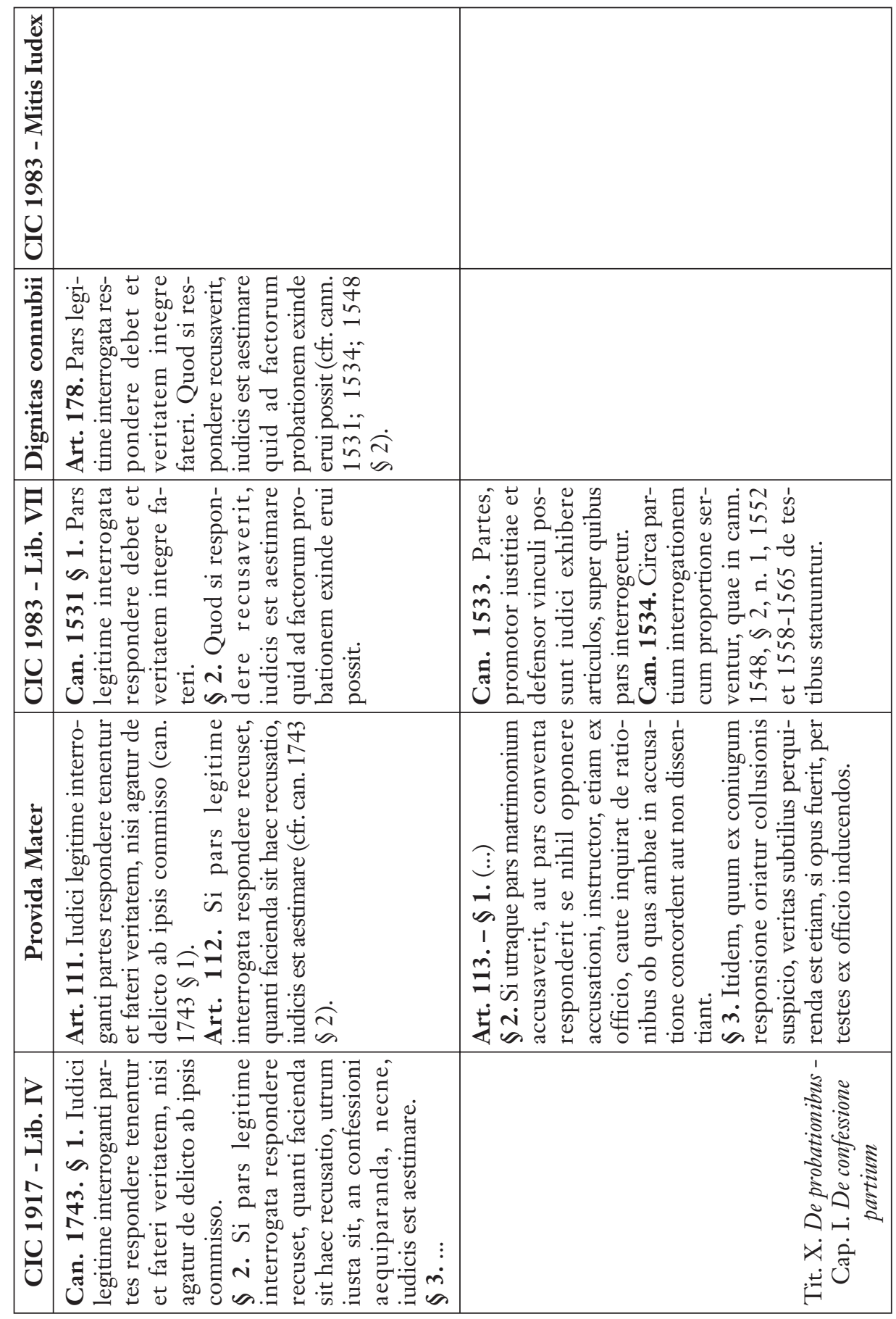




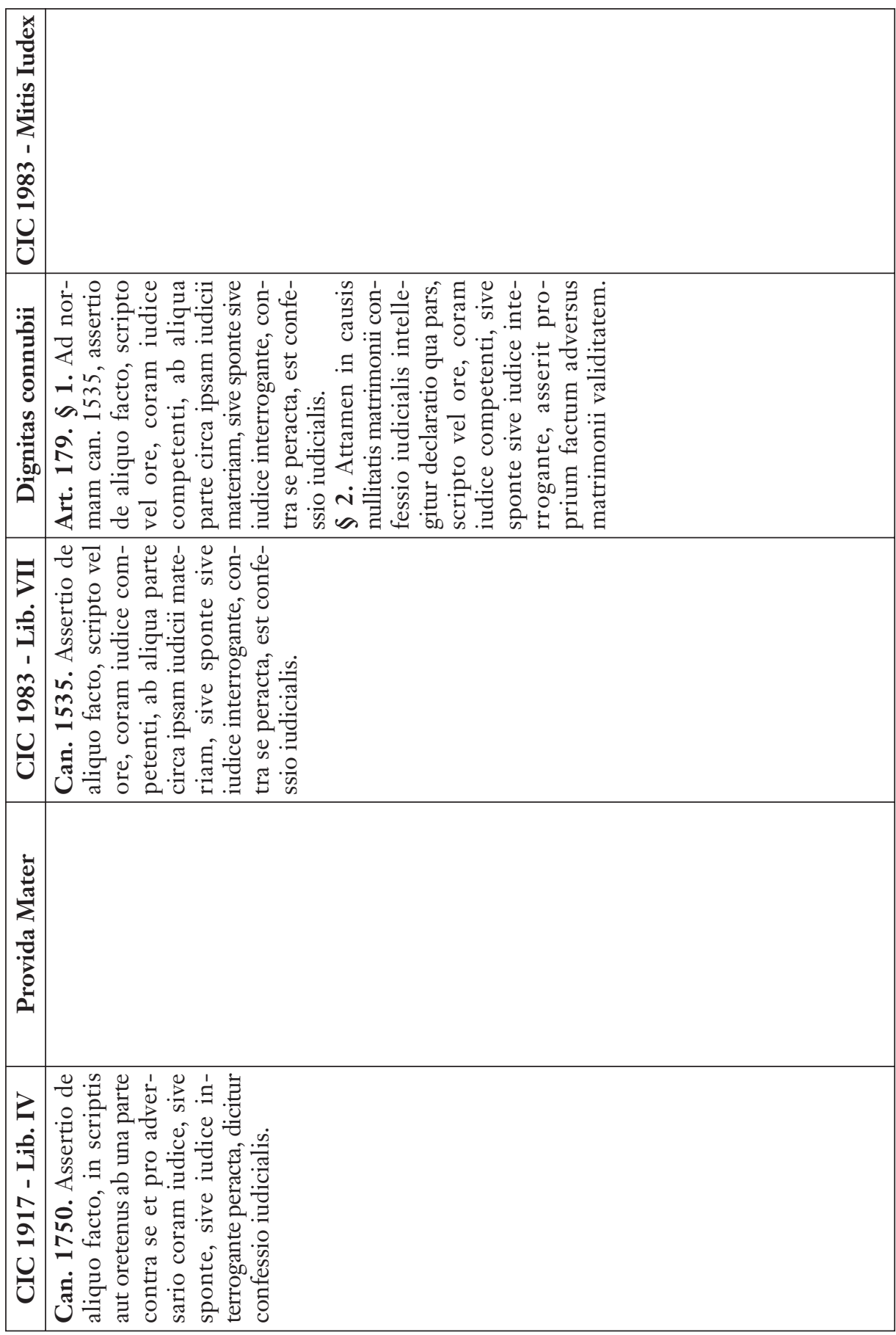




\begin{tabular}{|c|c|c|}
\hline 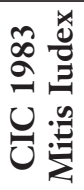 & & \\
\hline 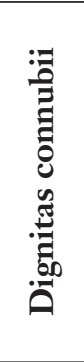 & 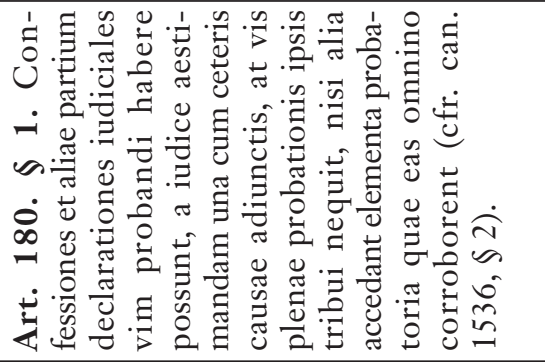 & 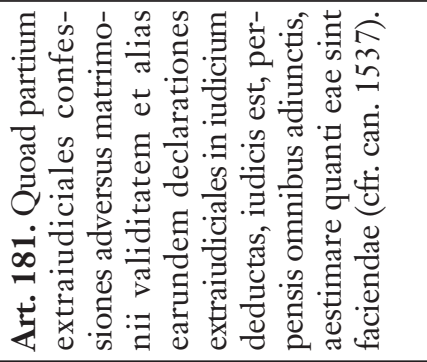 \\
\hline 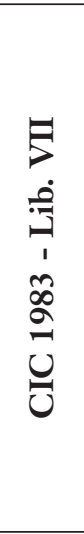 & 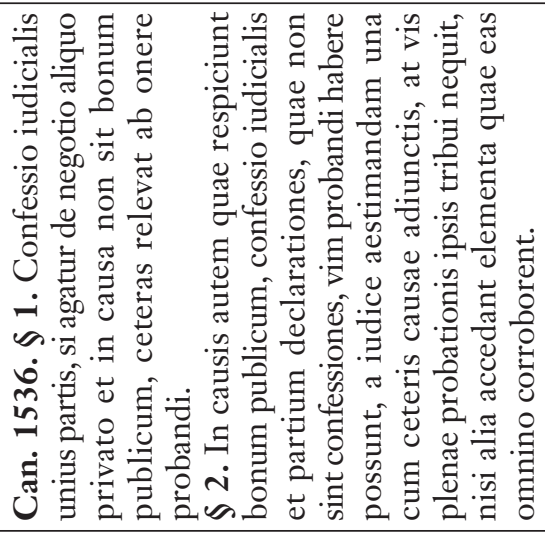 & 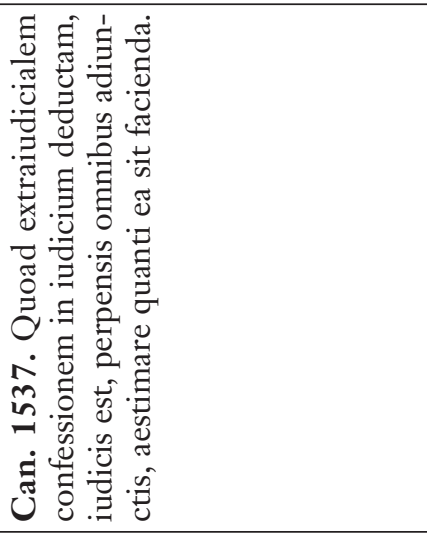 \\
\hline 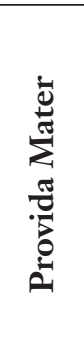 & & 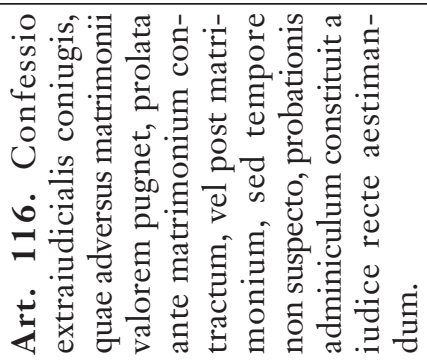 \\
\hline 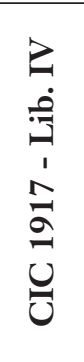 & 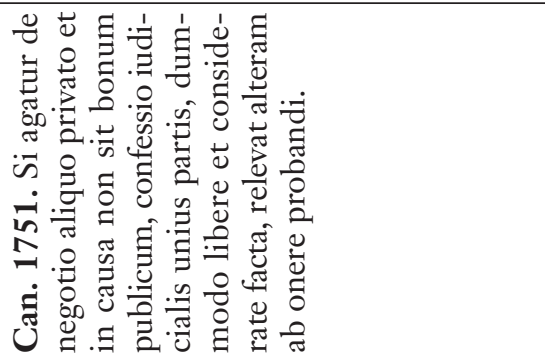 & 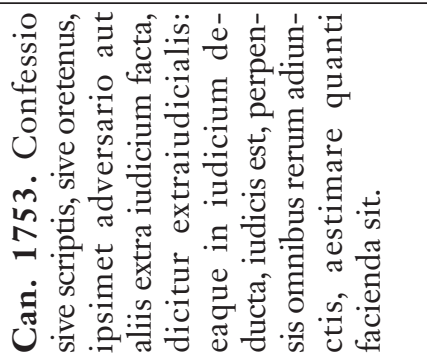 \\
\hline
\end{tabular}




\begin{tabular}{|c|c|c|}
\hline 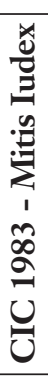 & & 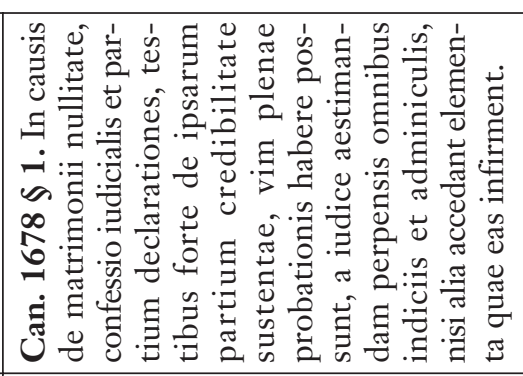 \\
\hline 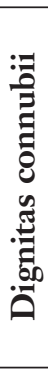 & & 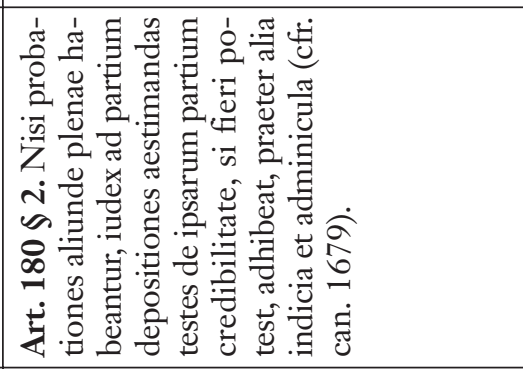 \\
\hline 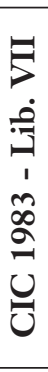 & 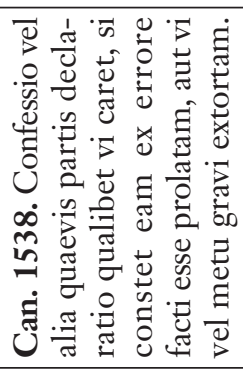 & 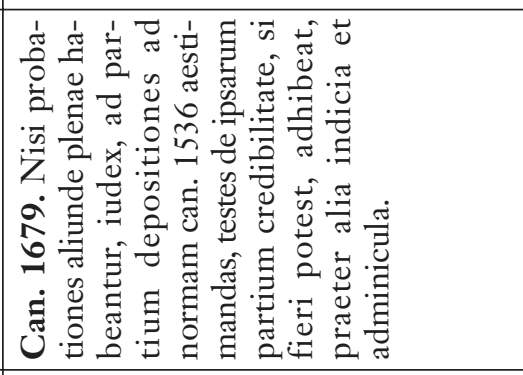 \\
\hline 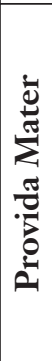 & & 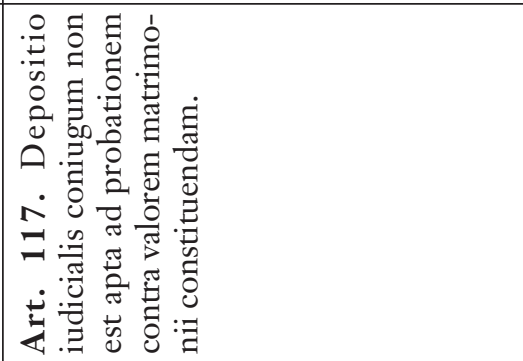 \\
\hline 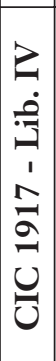 & & 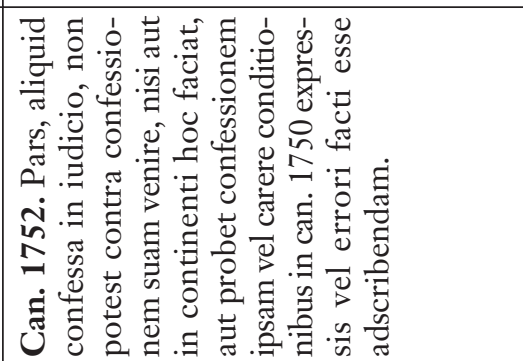 \\
\hline
\end{tabular}


En la comparación de estos textos se suelen contraponer un antes y un después, tanto que se puede hablar aquí también como de un giro, de una conversión, de una superación de prejuicios acerca de las declaraciones de las partes. El antes estaba caracterizado por una cierta desconfianza prejudicial que llevaba a suponer tendencial falsedad en el interesado, quien buscaría a toda costa llevar el agua a su molino; lo que en terminología forense se expresaba constatando cuan facile est pro se mentiri ya que nemo contra se agere censetur $^{6}$; motivo por el cual estaban excluidas como medio de prueba, aunque la jurisprudencia nunca lo entendió asî́. Hoy esta actitud de sospecha apriorística sería inadmisible; ha sido sustituida por lo que viene a llamarse optimismo antropológico típico del cristianismo que rezuma del Evangelio (curiosamente recóndito; tardía pero felizmente descubierto en la época del politically correct), en virtud del cual cambian las tornas, ahora se da por sentado que cualquier declarante en juicio dice en principio la verdad, o al menos no miente y esto lo hace creíble. Pero son cosas diferentes. Lo que está en juego, el objeto directo de la prueba, son los hechos causa de nulidad no la probidad del declarante.

Diversos comentarios podrían hacerse sobre esta reversión pendular que incide particularmente sobre el valor de las declaraciones de las partes. Buena parte de la doctrina, tras dar la bienvenida al cambio de actitud, procura recuperar una cierta 'normalidad' advirtiendo que ello no significa la ingenua aceptación acrítica de cualquier afirmación que provenga de las partes ${ }^{8}$ y tanto menos atribuirle tal valor de prueba que haga innecesaria cualquier otra verificación procesal ${ }^{9}$. Como muchos otros, también pienso que el respeto y confianza que merecen todas las personas implicadas en un proceso, las partes entre ellas, se compaginan con la conocida regla de experiencia nemo sibi iudex ${ }^{10}$.

\footnotetext{
${ }^{6}$ Según el caso. Por ejemplo en los de dolo, metus o simulación, al causante se le podría aplicar el aforismo nemo auditur propriam turpitudinem allegans; de ahí que se le negara incluso legitimación activa.

7 Baste como muestra el valioso volumen de L. DEL AMO, Interrogatorio y confesión en los juicios matrimoniales, Eunsa, Pamplona 1973, 594 pp.

8 «Bisogna sottolineare che interpretazioni ingenue e superficiali del can. $1678 \$ 1$ non giovano all'accertamento de la verità e, se malintese, rischiano di condurre impropriamente alla "autocertificazione" della nullità» (M. DEL Pozzo, Il processo..., cit., 182 y nota 49).

${ }^{9}$ Cabe preguntarse en efecto, si este evangélico optimismo tiene igual aceptación en las causas penales, en particular sobre ciertos delitos más graves.

${ }^{10}$ Nemo iudex in propria causa. Tomado de R. Domingo (dir.), Principios de derecho global, ThomsonAranzadi, Pamplona 2003, 154.
} 
Por lo mismo que no se puede ni debe ser testigo en causa propia ${ }^{11}$, las declaraciones de las partes no son testimonios, son alegaciones o confesiones, siempre supuesto el contradictorio.

Quizá estas y otras perentorias afirmaciones de los aforismos clásicos han de ser tomadas no tanto bajo el aspecto moral como el sicológico, el de la asunción de la experiencia en la memoria. A este propósito se pregunta Zuanazzi «sotto l'aspetto psicologico, era davvero ingiustificata la diffidenza di ieri? È del tutto gratuita la fiducia odierna? Non c'è dubbio che anche nella dichiarazione delle parti può essere turbata l'estensione della memoria e soprattutto la sua fedeltà per tutti quei meccanismi e quelle influenze affettive di cui abbiamo parlato. E c'è anche di più. Per forza di cose ciascuno dei contraenti, indipendentemente dall'essere attore o convenuto, tende a salvaguardare la propria immagine mediante meccanismi di difesa (inconsapevoli) o misure di sicurezza (coscienti). Soprattutto l'orgoglio -come si è detto- ha il potere di trasformare il ricordo. Le persone che hanno molto amor proprio non solo dimenticano ciò che è spiacevole al loro sentimento dell'io, ma trasformano anche a proprio favore ciò che esse o altri hanno detto o fatto. Questa falsificazione del ricordo si produce più facilmente quando due soggetti, come accade nel processo contenzioso, entrano in conflitto ed entrambi assumono atteggiamenti di attacco e di difesa, con accuse e colpevolizzazioni reciproche» ${ }^{12}$.

La inevitable carga de subjetividad de las declaraciones no significa que se les deba negar todo valor, significa más bien que en principio no bastan. Como dice Arroba Conde, una cosa es «que la verdad subjetiva de cada parte sea insuficiente» y otra que carezcan de ningún valor ${ }^{13}$.

Por otra parte al juez no le interesa directamente saber si una persona le está mintiendo, sino si le está diciendo la verdad objetiva. No es idéntico el significado de verdadero o falso cuando se aplica a una persona que cuando se aplica a un dicho o afirmación, en el primer caso puede ser ante todo una calificación moral que no cabe en el segundo. Se pueden decir cosas falsas siendo sinceros, «non basta che un individuo sia psichicamente normale e in buo-

${ }_{11}$ Nullus idoneus testis in re sua intellegitur (D. 22-V-10); ni a favor ni en contra. Ibid., 178.

12 G. ZuANAZZI, Psicologia e psichiatria nelle cause matrimoniali canoniche, LEV, Città del Vaticano 2006, 292-293.

13 M. J. ARROBA CONDE, Relación entre las pruebas y la comprobación de la verdad en el proceso canónico, Anuario de Derecho Canónico 1 (abril 2012) 27, nota 60. 
na fede perché la sua deposizione sia veritiera» ${ }^{14}$; $\ll$ es innegable -dice Del Amo- que sobre los hechos de su matrimonio y de su vida conyugal a los esposos no le falta de ordinario ciencia; pero también es verdad que, tratándose de hechos que tanto les afectan y que tanto dependen de su conducta, siempre les será difícil dejar de ser parciales» ${ }^{15}$. Se trata en principio de la más directa y completa narración del caso, que aunque adolezca de cierta subjetividad interesada, será tanto más digna de crédito en cuanto sea corroborada por otros elementos del sumario.

Por mi parte estimo arriesgado entender que el cambio de actitud de que venimos hablando equivalga a una inversión de presunciones: el verbo presumir en este campo podría tener a lo más un sentido coloquial ${ }^{16}$. Me parece que el punto de equilibrio entre los distintos planteamientos que caben en relación con las declaraciones de las partes se resume en verificación, comprobación: sea cual sea el valor que de entrada se les atribuya se ha de intentar al menos reunir otros elementos de prueba que de algún modo las avalen, sostengan o desmientan ${ }^{17}$; volviéndose a poner de manifiesto la relevancia de la actividad instructoria.

\section{a) En el Código de 1917}

El CIC 17 como se ha visto, incluía entre las pruebas solamente la confesión de las partes; no así las otras declaraciones ${ }^{18}$, de que se ocupaba inmediatamente antes, en el interrogatorio judicial de las partes que podía hacerse incluso antes de la litis contestatio (cc. 1742-1746). Era preceptivo «ad eruendam veritatem facti quod publice interest ut extra dubium ponatur», potestativo en los demás casos (c. 1742), con su cortejo de juramento y obligación sub

${ }^{14}$ G. ZuanazZI, Psicologia e psichiatria..., 293.

15 Interrogatorio y confesión..., cit., 4.

${ }^{16}$ De lo contrario habría que determinar el hecho incierto que se presume y el cierto que funda la presunción. Parece injustificado, cuando menos ocioso, seguir recurriendo a testigos y testimonios de probidad y credibilidad como hace la ley: si se presumen ¿a qué buscar atestados? (cfr. L. DEL AMO, Interrogatorio y confesión..., cit., 418-419).

17 Como dice C. Peña, «aun partiendo de la presunción de veracidad del declarante, es deber del juez valorar cuidadosamente la confesión judicial... para lo cual deberá contrastar la misma con las restantes pruebas... puesto que en las causas matrimoniales es fácil que el declarante no recuerde los hechos con objetividad. Así, puede pasar que, tras el fracaso conyugal, el cónyuge retrotraiga -inconscientemente- al periodo antenupcial una voluntad contraria al matrimonio mismo que en su momento realmente no existía...» (Matrimonio y causas de nulidad en el derecho de la Iglesia, Universidad Pontificia Comillas, Madrid 2014, 209).

18 Salvo las causas de impotencia e inconsumación (CIC 17 c. 1975). 
poena de decir la verdad. Se resalta su interés para la averiguación de los hechos, pero no se puede decir que no tuvieran ningún influjo en el ánimo del juez, ni siquiera ningún peso de prueba; de hecho la negativa a declarar quedaba explícitamente a la estimación del juez, que podía interpretarla como una confesión (c. $1743 \$ 2)$.

El concepto de confesión del viejo Código presupone un verdadero contradictorio, la existencia de partes opuestas en sus posiciones e intereses, entre las cuales surte efectos, pues la entiende como assertio de una parte contra se et pro adversario (CIC 17 c. 1750), siendo consecuencia típica de la judicial que releva a la otra parte de deber probar el hecho confesado cuando no está en juego el bien público, mientras la extrajudicial queda a la libre valoración del juez dentro del conjunto de las pruebas; sin particular normativa para las causas matrimoniales. Separándose del concepto codicial de confesión, la jurisprudencia habla ya de confessio o testimonium de la parte pro y contra matrimonii valorem; de esta última se afirma que no tiene valor de prueba, pero puede servir de adminículo para confirmar otras pruebas, e incluso servir como prueba de un hecho puramente interno a la parte ${ }^{19}$.

\section{b) La Provida Mater}

La Instrucción Provida Mater (15-VIII-1936) ${ }^{20}$ incluye la declaración judicial de los cónyuges entre las pruebas, colocándola tras la contestación de la litis (arts. 110-117) aunque decide que no es apta ad probationem contra valorem matrimonii constituendam (art. 117). Lo que no quiere decir que no tuvieran ningún valor, como tal vez alguien podría pensar ${ }^{21}$, sino que se les negaba valor de prueba plena contra la validez. El mismo Pompedda, mientras afirma que el art. 117 de la Provida Mater «ha dominato tutta la prassi anteriore al vigente Codice» ${ }^{22}$, reconoce que el principio allí fijado no impidió la introducción de otros criterios y prácticas, corrientes hasta el punto que -añade- aparte casos excepcionales, «la presunzione contenuta nel più volte citato art. 117

19 A. Ripa, cita varias sentencias en este sentido, si bien interpreta que ese valor adminicular sólo lo tenía si era favorable al vínculo, cosa que las sentencias citadas no dicen (La novità mancata..., cit., 71-73).

${ }^{20}$ Promulgada por Decreto de la S. Congr. de Sacramentos: AAS (1936) 313-372.

${ }^{21}$ Tal vez olvidando que la cuestión en estos juicios es an constet de nullitate y no utrum validus sit an non, el matrimonio en causa.

${ }^{22}$ M. F. POMPEDDA, Studi di diritto processuale canonico, Giuffrè, Milano 1995, 203. 
della Provida Mater, non è stata recepita dalla giurisprudenza rotale» ${ }^{23}$. De la misma opinión es Ripa quien observa como «sotto la vigenza del Codex de 1917 e della Provida Mater, sia stato spesso, benché non sempre, disatteso il divieto di attribuire un qualche valore probatorio alle dichiarazioni delle parti avverse alla validità del matrimonio» ${ }^{24}$.

La Instrucción prevé concretamente el litisconsorcio activo o que la parte demandada simplemente no se oponga; en tal caso insta al juez a en indagar los motivos de semejante concordancia, con particular finura si sospecha posible colusión entre las partes (art. $113 \$ \$ 2$ y 3).

\section{c) El Código de 1983}

El Código vigente sí se ocupa, y en primer lugar, de las declaraciones de las partes como medio de prueba, distinguiendo entre confesiones y otras declaraciones. La definición de lo que es confesión judicial (c. 1535) coincide con la del c. 1750 del CIC 1917 salvo que ahora basta que sea una assertio contra se peracta, no es preciso que sea pro adversario. Parece que se tiene menos presente el contradictorio y más la prevalencia de las causas matrimoniales; sin embargo la eficacia típica de la confesión judicial sigue siendo la misma: relevar a las otras partes del onus probandi allí donde no esté por medio el bien público (c. $1536 \$ 1)$.

Cuando sí lo está (c. $1536 \$ 2$ ), como es el caso de las causas matrimoniales, tanto la confesión en juicio como las demás declaraciones de las partes tendrán el valor probatorio que el juez prudentemente les atribuya dentro del conjunto instructorio; pero -se añade- no pueden alcanzar fuerza de prueba plena si no son confirmadas enteramente por otros elementos. El c. 1679, sobre las causas matrimoniales, reúne unas y otras bajo el concepto de partium depositiones, y precisa que el juez al estimarlas se sirva en lo posible de testigos de credibilidad de las partes (que no son lo mismo que los testimonios indirectos, del párroco por ejemplo, que se reciben por escrito y muy sucintos), junto con los demás indicios y adminículos resultantes, si éstos por sí solos no constituyen prueba bastante.

${ }^{23}$ Ibid., 207, cfr. 203-208. Cita como ejemplos las c. Mattioli de 24 de marzo del 1956, c. Felici de 2 de abril de 1957, entre otras, en las que la declaración de las partes fue prueba principal.

${ }^{24}$ La novità mancata..., cit., 75-82. Cita abundante jurisprudencia posterior a 1936. Parece pues que il divieto no era tan radical como este y otros autores estiman. 
Ésta es una de las novedades que introdujo el Código presente, haciéndose eco del magisterio del Vaticano II, de la jurisprudencia rotal y de buena parte de la doctrina: la declaración de las partes puede ser un medio de prueba principal, con frecuencia decisivo, en la ordenación procesal vigente como veremos.

\section{d) La Dignitas connubii}

La Instrucción Dignitas connubii ${ }^{25}$ aporta dos novedades interesantes para la doctrina. La primera (art. 179) se refiere a lo que se entiende por confesión judicial, que si en general sigue consistiendo en la admisión ante el juez de un hecho contrario al propio interés (c. 1535), en las causas matrimoniales intellegitur el aserto de parte de un hecho propio contrario a la validez del vínculo ${ }^{26}$.

No se trata, al menos directamente, de la pretensión de cambiar el concepto $^{27}$, si bien no faltan voces que así lo entienden y en verdad que se da pié para ello ${ }^{28}$, sino de la constatación de un uso del término que se ha extendido en el foro matrimonial. Cabe dudar que caiga en la potestad de ningún legislador cambiar el significado de un concepto jurídico tan venerable como el de confesión judicial, menos aún si no lo es. Si así no fuera, no se ve por qué entonces no se puede extender la posibilidad de 'confesar' contra vinculum a otros

${ }^{25}$ Aparte problemas antecedentes sobre su valor normativo, la vigencia de esta Instrucción tras el Mitis Iudex es discutida y en la práctica de no fácil determinación. Desde luego no parece compatible con la afirmación de que el Motu proprio efectúa una 'refundación' (o algo por el estilo) del procesal matrimonial. Lo que no empece su valor pedagógico. Vid. JAVIER OTADUY, El principo de jerarquía normativa y la Instrucción Dignitas connubii, Ius Canonicum 46 (2006) 59-97; E. BAURA, Il valore normativo dell'Istruzione Dignitas Connubii, en P. A. BONET - C. GULlo (cur.), Il giudizio di nullità matrimoniale dopo l'Istruzione «Dignitas Connubii». Parte prima: i principi, LEV, Città del Vaticano 2007, 185-211; M. DEL Pozzo, L'organizzazione giudiziaria ecclesiastica alla luce del m. p. «Mitis iudex», Stato, Chiese e pluralismo confessionale 36/2015 (23 novembre 2015) 1 (www.statoechiese.it).

${ }^{26}$ De «equivoco terminologico» lo califica A. Ripa, que describe y el origen y discute el alcance de este aserto en La novità mancata..., cit., 9 (nota 14) y 202-207.

27 De ser así, desde el escrito de demanda hasta la declaración de las partes estaríamos ante un mar de confesiones judiciales; por no hablar del concepto paralelo de confesión extrajudicial que sería lógico deducir.

${ }^{28} \mathrm{Si}$ se tiene en cuenta que existe «la tendenza ad attribuire aprioristicamente e formalisticamente, valore di prova piena alle dichiarazioni delle parti "pro nullitate vinculi"», presumiendo en quien las hace tal rectitud que exigiría un crédito indubitado (J. LlobelL, La genesi dei disposti..., cit., 144). 
sujetos como el metum incutiens o el dolum patrans, sean o no parte en el proceso, pues admiten hechos propios ${ }^{29}$.

Por otra parte no es la única 'corruptela' terminológica que se va introduciendo y que con el tiempo podría desde luego cambiar el significado del concepto; también es hoy corriente llamar testimonio a escritos memoriales, informes o atestados de probidad o credibilidad y otras declaraciones escritas que no constituyen lo que en derecho se entiende precisamente por testimonio, o sea las actuaciones resultantes del examen del testigo según las normas procesales (cc. 1558-1571). Lo mismo sucede con llamar apelación automática al envío ex lege de las actas y sentencia de primera instancia al tribunal superior, etc.

Sea lo que fuere, el art. $180 \$ 1 \mathrm{DC}$, como correspondiente al c. $1536 \$ 2$, deja el valor de las confessiones et aliae partium declarationes a la estimación del juez en el conjunto de las circunstancias de la causa ${ }^{30}$; advirtiendo $(\$ 2)$ que no se les atribuya el valor de plena prueba nisi alia accedant elementa probatoria que eas omnino corroborent. Y aquí incide la segunda novedad que introduce la Instrucción en nuestro tema y la doctrina subraya, es decir: la calidad de probatoria que deben tener esos alia elementa que corroboren la declaración de las partes, para que pueda hacer prueba plena. Ripa relata con detalle el quisquilloso itinerario redaccional de este añadido con el que se pretendía «evitare gli abusi di una lettura troppo liberal dell'articolo» ${ }^{31}$; Ortiz señala que tal vez la precisión no era necesaria en cuanto la doctrina en general así venía interpretando el c. $1536 \$ 2$; entiende que «il giudice cerca di raggiungere la certezza necessaria valutando le dichiarazioni giudiziali delle parti insieme ad altre prove ed elementi probatori»; cuando de ese conjunto no le resultase la prueba

${ }^{29}$ A fuer de precisos sería idealmente más adecuado considerar confesión la admisión de hecho pro validitate, o más bien contra optatam nullitatem; aunque lo que hace el legislador, dejar al juez la valoración de cualquier resultado del examen de las partes, parece lo mejor. Lo que no creo sería lógico es afirmar que en las causas matrimoniales no puede hablarse propiamente de confesión para luego formular una acepción tan impropia de la misma que exige sea contra vinculum. Vid. nota 76.

${ }^{30}$ En definitiva, dice M. Á. Ortiz, esta disposición puede simplificar las cosas: «tutte le dichiarazioni delle parti sono appunto dichiarazioni, non confessioni se non nel senso improprio dell'art. $179 \$ 2$, confessioni queste alle quali non si può dare una forza diversa del resto delle dichiarazioni» (La forza probatoria delle dichiarazioni delle parti nelle cause di nullità di matrimonio, en H. FrANCESCHI - M. Á. ORTIZ, Verità del consenso e capacità di donazione, Edusc, Roma 2009, 409; IDEM, La certezza morale..., cit., 6/22).

31 La novità mancata..., cit., 209-218. Más adelante considera el inciso «forse pleonastico e potenziale fonte di equivoci» (ibid., 224-225). 
suficiente (nisi probationes aliunde plene habeantur) entonces recurrirá a otros indicios, adminículos y en lo posible a testimonios de credibilidad ${ }^{32}$.

\section{e) El Mitis Iudex}

El Motu proprio Mitis Iudex avanza todavía en la atribución de valor probatorio a las declaraciones de las partes precisamente en las causas matrimoniales de nulidad, al formular en sentido positivo la posibilidad de que hagan prueba plena y reducir las posibilidades de que no la puedan hacer. Se pasa del vis plenae probationis ipsis tribui nequit, nisi alia accedant elementa quae eas omnino corroborent del c. $1536 \$ 2$ (en vigor para las demás causas que afectan al bien público), al vis plenae probationis babere possunt..., nisi alia accedant elementa quae eas infirment del nuevo canon $1678 \$ 1$ (para las causas matrimoniales); pero permaneciendo siempre en el terreno de la posibilidad en el que se inscriben los principios de libre valoración de la prueba y de certeza moral, o sea, dejando la cosa a la estimación del juez perpensis omnibus indiciis et adminiculis, dentro del conjunto de las actuaciones procesales, entre las cuales se contará en cuanto sea posible y necesario con testigos de credibilidad.

Así las cosas y según como se mire, se podría decir que todo sigue prácticamente como antes ${ }^{33}$ o bien recalcar que el Motu proprio ha significado un reconocimiento importante del valor de la declaración de las partes ${ }^{34}$. A mi en-

32 M. Á. ORTIZ, La forza probatoria..., cit., 410-411.

33 Para P. Moneta «il nuovo canone, più che una novità sostanziale, introduce un cambiamento di prospettiva che conferma ed avvalora le posizioni più aperte già assunte dalla precedente dottrina» [La dinamica processuale nel M.P. «Mitis Iudex», Ius Ecclesiae 28 (2016) 53, nota 11]. J. Llobell, estima asimismo que la novedad no es tan grande como aparenta, «poiché entrambi gli impianti normativi, nella pur loro evidente dissomiglianza testuale, richiedono condizioni applicative analoghe» [Alcune questioni comuni ai tre processi per la dichiarazione di nullità del matrimonio previsti dal M.P. «Mitis Iudex», Ius Ecclesiae 28 (2016) 29]. P. Toxé, expresa bien esta perspectiva diciendo que «le nouveau canon $1678 \$ 1 \mathrm{CIC}$, ne dit pas vraiment autre chose, même s'il le dit autrement» (La réforme des procés en nullité de mariage en Droit canonique latin selon le motu proprio Mitis Iudex Dominus Iesus, en C. Dounot - F. Dussaubat (dirs.), La réforme des procédures des nullités de mariage. Un étude critique, Artège Lethielleux, Paris 2016, 110. P. Bianchi, asimismo entiende que a pesar de la puesta en positivo del nuevo can. $1678 § 1$ «una analisi credo pacata delle condizioni previste circa la possibilità che esse acquisiscano valore di prova piena porta a concludere che la relativa disciplina non è mutata di molto» (Il servizio alla verità..., cit., 100).

34 Así C. Peña, considerando insuficiente el uso hecho hasta ahora de las posibilidades abiertas por el CIC, saluda el cambio como encomiable insistencia «del motu proprio Mitis Iudex en esta cuestión, con la presentación "en positivo" de esta eficacia en el nuevo can. 1678, 1» [El nuevo proceso «breviore coram episcopo» para la declaración de la nulidad matrimonial, Monitor Eclesiasticus 
tender ambas posiciones tienen su parte de verdad: el nuevo canon facilita al juez persuadido de la verdad de las afirmaciones de las partes la motivación in facto de la sentencia; si por el contrario no le bastan esas declaraciones para llegar a la certeza de la nulidad tendrá que explicar por qué las considera insuficientes; y como dice G. Boni, «risulta comunque assai diverso dovere cercare conferme ovvero attestare l'assenza di smentite ${ }^{35}$. Si se trata en cambio de determinar cómo el juez puede alcanzar la certeza necesaria, es claro que ésta debe buscarse -como siempre- en todas las actuaciones instructorias, que por escasas que fueren difícilmente se limitarán a unas declaraciones perfectamente unívocas, siempre habrá otros elementos al menos de hecho.

En la creciente estima procesal de la declaración de las partes ha influido seguramente el deseo de resolver las llamadas nulidades de conciencia, situaciones en las que la razón de la nulidad es un hecho o acto ocurrido en lo íntimo del sujeto, que está convencido de la nulidad de su matrimonio pero no puede demostrarla en juicio, en el sentido de que su sola declaración no basta. A ellas se refería explícitamente, antes de la promulgación del CIC, la $F a$ miliaris consortio, al hablar de «los que han contraído una segunda unión en vista a la educación de los hijos, y a veces están subjetivamente seguros en conciencia de que el precedente matrimonio, irreparablemente destruido, no había sido nunca válido» (n. 84) ${ }^{36}$.

La Carta de la Congregación para la Doctrina de la Fe, sobre la recepción de la comunión eucarística por parte de los fieles divorciados que se ban vuelto a ca$s^{3}{ }^{37}$, haciéndose eco precisamente de este pasaje sobre las nulidades subjetivas, afirma que «es necesario discernir a través de la vía del fuero externo establecida por la Iglesia si existe objetivamente esa nulidad matrimonial»; en vista de lo cual, recuerda como «la disciplina de la Iglesia, al mismo tiempo que confirma la competencia exclusiva de los tribunales eclesiásticos para el examen de la validez del matrimonio de los católicos, ofrece actualmente nue-

CXXX (2015) 576]. M. Á. Ortiz, condivide esta opinión en cuanto que «Peña ritiene che MI ha esplicitato una previsione presente nella legislazione precedente, anche se poco esplorata» M. Á. ORTIZ, Le dichiarazioni delle parti e la prudente valutazione della loro forza probatoria, en H. FRANCESCHI - M. Á. ORTIZ (cur.), Ius et matrimonium II. Temi processuali e sostanziali alla luce del Motu Proprio Mitis Iudex Dominus Iesus, Edusc, Roma 2017, 239.

35 La recente riforma del processo di nullità matrimoniale. Problemi, criticità, dubbi (parte terza), Stato, Chiese e pluralismo confessionale 11/2016 (21 marzo 2016) 29.

${ }^{36}$ San Juan Pablo II, Exhortación Apostólica Familiaris consortio (22-XI-1981), AAS 74 (1982) 81191.

37 Del 14 de septiembre de 1994, AAS 86 (1994) 974-979. 
vos caminos para demostrar la nulidad de la anterior unión, con el fin de excluir en cuanto sea posible cualquier diferencia entre la verdad verificable en el proceso y la verdad objetiva conocida por la recta conciencia» $(\text { n. } 9)^{38}$. Seguramente la más alta valoración procesal de que goza hoy la declaración de las partes abre posibilidades mayores a la solución de estos casos dramáticos. $\mathrm{Al}$ mismo tiempo no sería bueno olvidar que la persuasión de los protagonistas de la nulidad ab origine de su matrimonio es necesariamente subjetiva, nacida precisamente a raíz del fracaso de aquél, su certeza moral no es aquella que el juez debe alcanzar, por lo que éste no deberá limitarse a ser el simple trámite por el que la íntima convicción de las partes de subjetiva deviene objetiva; el juez no es un simple notario ni puede hacer certeza moral suya la certeza moral de las partes por la mera y sincera declaración judicial de éstas.

Después de este breve recorrido por la historia legal de la declaración judicial de las partes en los procesos matrimoniales, creo interesante observar que, de un modo u otro, todos los textos distinguen conceptualmente entre confesión y otras declaraciones de las partes ${ }^{39}$, pero no atribuyen a ninguna de ellas un mayor o menor valor de prueba, más bien las equiparan, dejando unas y otras a la estima del juez dentro del conjunto de los resultados de la instrucción $^{40}$. Y en verdad que en las causas matrimoniales al menos, con frecuencia no será fácil calificar de confesión una afirmación de parte; se reconocen hechos, cuya calificación jurídica pertenece al juez y no siempre será inmediata y evidente. Desde luego es más bien académico pensar que alguien confiesa

${ }^{38}$ Nota 18 del original: «cfr. Código de Derecho Canónico, cann. $1536 \$ 2$ y 1679 y Código de los cánones de las Iglesias Orientales, cann. $1217 \$ 2$ y 1365, acerca de la fuerza probatoria de las declaraciones de las partes en dichos procesos». El texto citado parece confundir recta conciencia con conciencia verdadera.

39 Llobell estima que en las causas matrimoniales no puede hablarse de confesión pues no existe, dice, la posibilidad de declarar contra sí (J. Llobell, I processi matrimoniali nella Chiesa, Edusc, Roma 2015, 206-207; IDEM, La genesi dei disposti..., cit., 143-144, también en btcaev p. 43); tal vez porque sitúa inmediatamente la cuestión en el plano moral, centrándola sobre el hecho clave a probar: la nulidad culpablemente causada. Pero ni todas las nulidades provocadas lo son culpablemente (lo que además sólo interesa relativamente), ni los únicos hechos confesables son la simulación el engaño o la violencia. Es cierto, sin embargo, -como dice el mismo autor- que hay que situarse en el interés procesal (real, no formal) del que confiesa, para calibrar si la afirmación es realmente contra se o en favor propio; p. e., si el demandado confiesa que simuló tal vez lo que está simulando es su condición de demandado, que en tal caso sería puramente formal; para que fuera confesión tendría que verificarse su real oposición a la declaración de nulidad.

40 Cfr. J. M. SERrano Rutz, Confessione e dichiarazione delle parti nella giurisprudenza della Rota, en S. GHerro (cur.), Confessione e dichiarazione delle parti nelle cause canoniche di nullità matrimoniale, Padova 2003, 150-152; que también considera equívoca la distinción entre confesión y declaración de las partes en estas causas. 
algo en términos técnicos, rotundos e inequívocos ${ }^{41}$, lo normal es que el interesado se exprese de forma que sus afirmaciones puedan encontrar su sentido genuino dentro del entero interrogatorio y aún del sumario. A su vez, el hecho confesado no siempre será el objeto directo de la prueba; pueden confesarse hechos que parcialmente contribuyan a esclarecer la verdad histórica. Por ejemplo, sería confesión (aunque por otras razones no alcance su efecto típico), si quien dice haber excluido la prole, declara que usó a tal fin medios contraceptivos objetivamente inadecuados o sin pervicacia; o si el supuesto simulador declara que estaba enamorado de la otra parte; o que fue ésta la que tomó la decisión de interrumpir la convivencia; o que ésta se produjo por motivos totalmente ajenos a dudas o rémoras prenupciales.

En todo caso una cosa es que las deposiciones de las partes puedan hacer prueba plena y otra cosa es que la hagan de por sí: que obtenidas y fiables, ya no sean necesarias mayores o ulteriores indagaciones a través de otros medios de prueba; si así fuera es claro que raramente se encontrarían alia elementa que las puedan confirmar o desmentir, ni otros indicios o adminículos con los que contrastarlas (MI c. $1678 \$ 1$ ). Me parece plausible la opinión de Moneta según la cual no es útil ni conveniente que la ley (c. $1536 \$ 2$ ) hable de prueba plena con referencia a las deposiciones de las partes, sino que podría limitarse «a prescrivere che le confessioni e le altre dichiarazioni giudiziarie delle parti "vim probandi babent, a iudice aestimandam una cum ceteris causae adiunctis" ${ }^{42}$.

Por su parte Ortiz, afirma que la posibilidad de decidir una causa sobre la base de la sola declaración de las partes puede darse «eccezionalmente en el processo ordinario, non invece nel processus brevior. Da una parte perché il can. 1683 riserva la procedura più breve per le cause nelle quali "ricorrano circostanze di fatti e di persone sostenute da testimonianze e documenti, che non richiedano una inchiesta o una istruzione più accurata e rendano manifesta la nullità" il che presuppone che oltre le dichiarazioni ci sono altri elementi probatori che giustificano il ricorso alla procedura abbreviata. Ma soprattutto è la stessa natura delle cose ad escludere tale possibilità: le dichiarazioni delle parti possono sostenere da sole la certezza del giudice che non è riuscito ad otte-

${ }^{41}$ Expresiones tales como: excluí la prole, me reservé ser o no fiel, cometí dolo, amenacé, etc. más bien serían poco convincentes.

42 Processo di nullità, matrimonio e famiglia nell'attuale dibattito sinodale, Stato, Chiese e pluralismo confessionale 8/2015 (7 marzo 2015) 18 (www.statoechiese.it). L. del Amo proponía ya lo mismo pero dando por descontado que no podía hacer prueba plena (Interrogatorio y confesión..., cit., 416). 
nere altre prove, il che comporta implicitamente un'istruttoria più complessa di quella essenziale prevista per il processus brevior ${ }^{43}$.

A este fin, los criterios del c. 1572 para la valoración de los testimonios, pueden tener aplicación adecuada en la evaluación de la deposición de las partes. El juez por tanto tendrá en cuenta la condición y honradez de la persona (y aquí entran los testigos y atestados de fama y credibilidad), si habla de ciencia directa o de relato, la coherencia, constancia y seguridad con que hace su declaración, si en fin ésta es verosímil y confirmada o no por los testigos y demás elementos de prueba.

\section{LA RELEVANCIA DE LA DECLARACIÓN DE LAS PARTES PARA LA ADQUISICIÓN DE LA VERDAD}

Entramos así en el segundo tema sobre el que quisiera detenerme: la importancia real de las declaraciones de las partes en orden al conocimiento de los hechos sobre los que debe recaer la decisión. «Valorar los relatos de las partes no es sólo conocer y apreciar su eficacia directa e inmediata respecto a la formación de la certeza necesaria para que el juez dirima la controversia; sino también tomar de esas declaraciones, examinadas y criticadas con diligencia, todo cuanto contribuya a concretar los límites de la controversia, y recoger en ellas los indicios que surjan y que puedan ser útiles para elegir los medios de prueba pertinentes en orden a obtener certeza de la verdad histórica de los hechos controvertidos» ${ }^{44}$.

Independientemente del valor que la ley procesal haya dado a la declaración de las partes como medio de prueba en el pasado, es indudable que la misma ley la ha considerado siempre un recurso imprescindible para el establecimiento de la verdad; el CIC 17, aunque no la estima prueba formal (como no sea confesión), considera en cambio importante el examen de las partes, que sistemáticamente precede al Título De probationibus. El juez puede hacer e iterar ese interrogatorio en cualquier momento (también de oficio): debe hacerlo para aclarar algo que afecta al interés público, puede hacerlo a instancia de parte o de oficio, no como prueba -se decía- sino para completar o dilucidar

43 M. Á. OrTiz, Le dichiarazioni delle parti..., cit., 258.

${ }^{44}$ L. DEL AMO, Interrogatorio y confesión..., cit., 267. Al ilustrar profusamente la utilidad, fines y características del examen de las partes, señala el de la inmediación: oír el relato de los hechos directamente de los protagonistas y no a través de escritos de terceros (ibid., 27-32). 
una prueba presentada (c. 1742 CIC 17). La doctrina considera útil interrogar a las partes antes de comenzar la recogida de pruebas, pues ellas mismas son fuente de prueba: las deducciones de defensor del vínculo y sobre todo del juez, las conclusiones de los peritos, etc. tendrán como punto de partida los dichos de las partes.

La Provida Mater (1936) pide que el juez examine a las partes, empezando por la actora, inmediatamente después de la litis contestatio (art. 110).

El Código vigente, pues que ya la considera prueba en sí, mantiene la facultad del juez de interrogar a las partes ad veritatem aptius eruendam, y el deber de hacerlo para probar un hecho cuya aclaración es de interés público (c. 1530).

$\mathrm{Al}$ deber del juez de interrogar, corresponde siempre el de las partes de veritatem (integre) fateri; la renuencia de alguna de ellas a responder será estimada libremente por el juez en orden a la prueba de los hechos (c. $1743 \$ 2$ CIC 17, Provida Mater, art. 112, c. $1531 \$ 2$ CIC). Señales todas éstas de la utilidad y prestancia que tiene por sí misma la declaración de las partes para la instrucción de las causas matrimoniales, asunto que quisiera abordar en relación con el reciente proceso más breve introducido por el Mitis Iudex.

\section{EL PROCESSUS BREVIOR}

Este proceso constituye, junto a la supresión de la doble conforme y a la consagración del juez único, un punto principal de una reforma que por su radical novedad, características y pretensiones, no exentas de ambigüedades y paradojas, necesariamente tenía que suscitar perplejidad en quienes están llamados a actuarla y a estudiarla ${ }^{45}$. Las posiciones doctrinales oscilan entre el entusiasmo y la crítica más o menos abierta ${ }^{46}$, quedando entre ambos amplio espacio a la acogida, la moderación, al contraste entre los defectos de lo de antes y las virtudes de lo nuevo, al acatamiento, tal vez arrimado al repliegue de un categórico iusum quia iustum a un más modesto iustum quia iusum, que al cabo también con unos alicates se puede clavar un clavo.

45 Vid. entre otros G. BonI, La recente riforma del processo di nullità matrimoniale. Problemi, criticità, dubbi (obra en tres partes, citada en la Bibliografía).

46 Tal vez anónima, como el autor que escribe bajo el pseudónimo EBED-MELEK, Breves remarques sur le Motu Proprio «Mitis Fudex» du Pape François, http://www.verites-catholiques.fr/mitis-judexcommentaire-ebed-melek/. 
Paralelamente la naturaleza judicial del proceso es discutida. Algunos, mediante el recurso a argumentos autorreferenciales, la sostienen simplemente porque así lo dice el proemio del Mitis Iudex, atribuyendo valor magisterial o performativo a afirmaciones de orden técnico-jurídico ${ }^{47}$. Otros consideran que la simplificación obrada en aras de la celeridad lo acerca mucho a un procedimiento administrativo, si no lo ha convertido en tal.

Desde luego la naturaleza administrativa o judicial de un procedimiento no se decide en base a declaraciones a priori sino a la realidad; pero hay un no sé qué de excusatio non petita que presta el flanco a las críticas. Otra cosa es que no siendo el derecho matemático exista una zona gris que da margen a la discusión científica ${ }^{48}$; así C. Peña califica este proceso como judicial, declarativo, especial y sumario en cuanto limitado en su alcance cognitivo ${ }^{49}$; Arroba Conde lo dice «Processo extra-ordinario, a cognizione sommaria» que «non altera la sostanza del Giudizio: rimane infatti Processo Giudiziale» ${ }^{50}$; Del Pozzo considera que, junto al tribunal diocesano ordinario, constituye «un'altra istanza di giustizia sommaria ma estremamente qualificata non professionalmente ma autoritativamente ${ }^{51}$. Pinto afirma que se trata de un proceso bre-

47 Aunque no se refiera explícitamente al proceso más breve, se suele citar el párrafo del proemio: «Quod fecimus vestigia utique prementes Decessorum Nostrorum, volentium causas nullitatis matrimonii via iudiciali pertractari, haud vero administrativa, non eo quod rei natura id imponat, sed potius postulatio urgeat veritatis sacri vinculi quam maxime tuendae: quod sane praestant ordinis iudiciarii cautiones». Mas nadie se extiende en explicar cómo es que la rei natura no impone el proceso judicial, mientras sí lo exige tutelar al máximo la verdad del sacro vínculo. ¿Será algo así como non nullitatis sed veritatis causa? ¿O quiere decir que por su naturaleza la 'cosa' podría ser resuelta con una cierta discrecionalidad constitutiva (oikonomia), pero que ello no apuraría la verdad sobre la existencia del vínculo? ¿O será más bien que la tutela de esa verdad es requerida por la naturaleza de la cosa?

${ }^{48}$ Por ejemplo, en qué medida se puedan en principio considerar garantizados el contradictorio, la defensa y la imparcialidad del juez, requisitos elementales del proceso, cuando éste se confía a un único juez, técnicamente no cualificado, asistido -si lo es- por dos asesores quizá igualmente ayunos de derecho (uno de los cuales debe de instruir el proceso en una única sesión), cuyas decisiones raramente serán sometidas a revisión; con posible asignación discrecional de patronos a las partes. Por no inquirir la medida en que se pueden considerar tuteladas la verdad y la indisolubilidad del vínculo confiadas a un defensor con limitados recursos procesales y no mayor preparación jurídica. ¿Puede un juez ser imparcial si no es algo experto en derecho? ¿Puede serlo el instructor? ¿Se respeta el derecho a la defensa si no se puede elegir el propio patrono?

49 C. PEÑA, El nuevo proceso «breviore coram episcopo» para la declaración de la nulidad matrimonial, Monitor Eclesiasticus CXXX (2015) 589-591.

${ }^{50}$ M. J. ARRoBa CONDE, Le «Litterae motu proprio datae» sulla riforma dei Processi di nullità matrimoniale: prima analisi, Apollinaris 88 (2015) 565.

${ }^{51}$ M. DEL Pozzo, L'organizzazione giudiziaria..., cit., 9. 
ve sobre el que «bisogna evitare i termini "sommario" e "amministrativo" $»^{52}$; Morán Bustos considera una premisa «la naturaleza declarativa de los procesos judiciales de nulidad de matrimonio»y pone de relieve las exigencias de esta afirmación, entre ellas el uso verdaderamente extraordinario del proceso brevior $^{53}$; Boni, en cambio, después de estudiar detenidamente sus características, concluye que se trata más bien de un proceso admnistrativo ${ }^{54}$.

El desarrollo de los acontecimientos dirá hacia donde propende el sistema más allá de las intenciones. Criterio de discernimiento serán la seriedad y pericia con que se lleve a cabo la instrucción, la cuenta en que se tenga la jurisprudencia a la hora de aplicar la ley matrimonial, la solidez de los motivos que sustenten las decisiones.

La rúbrica del Código (Lib. VII, P. III, Tit. I, Cap. I, Art. 5) lo llama processu matrimoniali breviore coram Episcopo, denominación de origen que la doctrina ha acogido sin dudar. Mas ya el IV Criterio fundamental y seguidamente los cánones lo llaman sólo proceso más breve; lo que parece más conforme a la realidad, siendo patente la ausencia del Obispo ${ }^{55}$ : no se trata de un proceso que tenga lugar coram episcopo $0^{56} \mathrm{o}$ sea dirigido por él, y menos de una episcopalis audientia como se podría imaginar ${ }^{57}$. En él se turnan tres agentes de la ac-

52 P. V. PINTO, La riforma del processo matrimoniale per la dichiarazione di nullità, L'Osservatore Romano, 8 settembre 2015, http://www.osservatoreromano.va/it/news/la-riforma-del-processomatrimoniale-la-dichiarazi\#.

53 C. M. Morán Bustos, El proceso «brevior» ante el Obispo diocesano: requisitos procesales y sustantivos de un proceso que ha de ser extraordinario, RGDCDEE 41, mayo (2016) 7; IDEM, Retos de la reforma procesal de la nulidad del matrimonio, Ius Canonicum 56 (2016) 28.

${ }_{54}$ G. BONI, La recente riforma..., cit., (parte seconda) 64-76.

55 Que del Pozzo, explica con razones prácticas de brevedad, y por «l'impossibilità di esigere un coinvolgimento tanto oneroso per l'ufficio capitale» (Il processo matrimoniale..., 171, nota 9).

${ }^{56}$ Salvo un uso de coram talmente versátil que equivalga a decir que el super rato es un procedimiento ante el Papa por el hecho de que decide él.

57 Tanto menos de una vuelta a los primeros siglos de la Iglesia, aunque el parangón pueda ser literariamente legítimo. Lo que se pide al Obispo es que en general procure que los fieles no vean las estructuras de la Iglesia como algo lejano y para eso que actúe personalmente también en materia judicial, concretamente en ciertos asuntos de nulidad de matrimonio, cuando la nulidad parezca prima facie fácil de constatar. Ya SAN JUAN PABLO II, en su último Discurso a la Rota (25-I-2005) decía: «ho più volte ricordato l'essenziale rapporto che il processo ha con la ricerca della verità oggettiva. Di ciò devono farsi carico innanzitutto $i$ Vescovi, che sono i giudici per diritto divino delle loro comunità. $\grave{E}$ in loro nome che i tribunali amministrano la giustizia. Essi sono pertanto chiamati ad impegnarsi in prima persona per curare l'idoneità dei membri dei tribunali, diocesani o inter diocesani, di cui essi sono i Moderatori, e per accertare la conformità delle sentenze con la retta dottrina. I sacri Pastori non possono pensare che l'operato dei loro tribunali sia una questione meramente "tecnica" della quale possono disinteressarsi, affidandola interamente ai loro giudici vicari (cfr. CIC, cann. 391, 1419, $1423 \$ 1$ )» [AAS (2005) 164-166], también en btcaah; cursiva original. El Papa Francisco cita este mismo texto en su sentencia de 13 de julio de 2017, n. 3. 
tividad judicial: Vicario, instructor y en fin el Pastor, quien se hace presente sólo al final, concluida la causa (si hubiera conclusio), para decidir en base a los autos y defensas que pueda haber y a los datos y valoraciones que le proporcionen el instructor y el asesor, a los que consultará ${ }^{58}$ tal vez escuchándolos. De modo que el Obispo además de ex actis probablemente decidirá ex auditis, tanto en lo que se refiere a los hechos como a su calificación jurídica. Si luego será él mismo quien personalmente redacte la sentencia o el decreto del caso, es algo que establecerá la praxis, posibilidades caben varias y en general los autores prevén y admiten que puede encargarlos al Vicario, al instructor o al asesor aunque los firme él ${ }^{59}$.

Sin duda es un avance que el Obispo conozca más de cerca y decida en persona algunas causas que afectan a su grey $^{60}$; no puede sin embargo decirse que este proceso más breve sea un alarde de inmediatez judicial: precisamente en esto contrasta con el contencioso oral (cc. 1656-1670), donde vige la unidad instructor-juez ${ }^{61} \mathrm{y}$ del que se han tomado incluso a la letra no pocos preceptos. En cuanto a celeridad tampoco el oral va la zaga del brevior, sobre todo en los plazos para la sentencia.

De otra parte, el ya citado $I^{\mathrm{o}}$ Criterio fundamental del Mitis Iudex, al anunciar la institución de este proceso precisa que está pensado como vía a seguir «en los casos en que la acusada nulidad del matrimonio esté sostenida por argumentos particularmente evidentes» ${ }^{62}$.

Argumentos evidentes que se sustancian en el concurso de circunstancias de personas y hechos, expuestos, breve, íntegra y claramente en la demanda que: a) sean fácilmente (brevemente) demostrables, en cuanto sostenidas de tal guisa por «testimonios o documentos» que no sea menester «una investiga-

58 P. Moneta, La dinamica processuale nel M.P. «Mitis Iudex», Ius Ecclesiae 28 (2016) 57-58.

${ }^{59}$ Me refiero a la redacción material, se supone que la decisión la toma el Obispo, su certeza moral no puede ser la de otro; cfr. J. LlObELL, El ejercicio personal de la potestad judicial del Obispo diocesano. Algunas consideraciones preliminares al M.P. «Mitis iudex» y al M.P. «Mitis et Misericors», RGDCDEE 41 (2016) 21.

${ }^{60}$ C. Peña considera que este proceso «presupone de algún modo una especial vinculación y cercanía entre los fieles que piden la nulidad y el Obispo diocesano que va a resolverlo» (El nuevo proceso..., cit., 575). Cercanía que las nuevas reglas de la competencia no siempre facilitan.

${ }^{61}$ Quizá la razón sea la escasez de tiempo del Prelado para seguir el caso desde el principio, aunque bien mirado y según las previsiones legales no deberían ser tantos los casos de nulidad evidente, ni tanto el tiempo que requieran si la instrucción se completa en una sesión.

62 Se alude como precedente o modelo inspirador al proceso documental, en el que la nulidad se deduce cierta y directamente de documentos irrefutables (c. 1688). 
ción o instrucción más precisa» ${ }^{63}$; b) que además «hagan manifiesta la nulidad» (c. $1683,2^{\circ}$, cfr. c. 1684$)$.

La preliminar apreciación de ambos requisitos corresponde al Vicario ${ }^{64}$, sea a instancia de las partes (o de una con el consentimiento de la otra), que presentan ya la demanda de acuerdo con lo dispuesto en el c. 1684, sea de oficio, porque vislumbra la evidencia de la nulidad en una demanda corriente y entonces procurará la adhesión de la otra parte (RP art. 15).

$\mathrm{Al}$ discernir que una causa debe tramitarse por lo breve el Vicario está implicando al Obispo mismo llamándolo a juzgarla (c. $1676 \$ 2$ ), lo que hace pensar que al tomar esa clase de decisones debe atender además a las indicaciones del Prelado ${ }^{65}$.

Ahora bien, cuando el Vicario establece que se siga este procedimiento, fijando al tiempo la quaestio decidendi, está ya haciendo un juicio sobre el fondo de tal cuestión favorable a la nulidad, así como sobre la suficiencia de los indicios aportados con la demanda. Se tratará quizá sólo de una suposición (cfr. c. 1676), pero que es determinante, también de la instrucción ${ }^{66}$, sobre todo si la realiza el mismo Vicario.

${ }^{63}$ Un parámetro objetivo en esta apreciación sería ponderar si esas pruebas pueden realizarse, según lo que establecen los cc. 1685 y 1686, en no más de 30 días y en una sola sesión.

${ }^{64}$ Dejo aparte los interrogantes sobre quién sea este Vicario.

${ }^{65}$ E. Napolitano sugiere que sea el Obispo quien reciba el escrito de demanda y lo trasmita al Vicario «in questo modo, al Vescovo diocesano verrebbe data anche la possibilità di svolgere la funzione pastorale e di conoscere i fedeli della propria Chiesa che vivono l'esperienza di un precedente matrimonio fallito e chiedono la dichiarazione di nullità... L'incontro con le parti, o almeno con una di esse, renderebbe anche più sereno il vescovo diocesano nel caso in cui, trattandosi di un processus brevior, dovrà emettere la sentenza... poi, potrebbe valutare insieme al proprio vicario giudiziale la possibilità di ammettere il libello e, nel caso, indicare che tipo di procedura seguire anche se, secondo il can $1676, \$ 2$, spetta al vicario giudiziale stabilire se "la causa debba trattarsi con il processo ordinario o con il processo più breve" $\gg[I l$ processus brevior nella Lettera Apostolica motu proprio datae Mitis Iudex Dominus Iesus, Monitor Ecclesiasticus CXXX (2015) 557-558]. Pero en este caso el procedimiento deviene una suerte de proceso oral quasi administrativo: no es pensable que habiendo el Pastor decidido -oídas las partes- por la vía brevior, vaya luego a definir el caso sólo ex actis (c. $1687 \$ 1$ ). Y es que, como digo, el proceso brevior nace con el prejuicio de partida de que la nulidad existe y es manifiesta (o fácilmente probable); lo que equivale a una presunción de nulidad, que sólo unos resultados instructorios claramente adversos podrá destruir. Por lo mismo es oportuno que el Obispo no intervenga personalmente en la investigación prejudicial o pastoral, así interpreto RP arts. 2 y 3; si lo hubiera hecho se debería seguir la vía ordinaria; lo mismo vale para todos los demás que intervengan en dicha investigación: deben abstenerse de participar en el proceso (cfr. J. LLOBELL, Alcune questioni comuni..., cit. 27; G. BoNI, La recente riforma..., cit. [parte terza], 59-60).

${ }^{66}$ C. Peña, advierte que el Vicario, al decidir sobre el uso del proceso más breve «debe evitar tanto el peligro de prejuzgar la causa como el de admitir sin base suficiente un proceso extrarordinario», que requiere para su utilización «que las circunstancias concurrentes y la prueba aporta- 
Existen otros juicios preliminares en ámbito canonico, civil, penal o internacional, que versan normalmente sobre la admisibilidad del pleito; juicios que cuando son favorables dejan intacta la questión de fondo y cuando son negativos declaran la pretensión manifiestamente infundada, no manifiestamente fundada como parece suceder en nuestro caso; siempre motivando lo decidido ${ }^{67}$. En proceso brevior más bien se trata de declarar in limine litis la manifiesta solidez de la pretensión actora ${ }^{68}$, dadas las circunstancias.

Se comprende pues que la definición de la causa no competa al mismo Vicario que ya la ha prejuzgado en cierto modo, eso pondría en entredicho la naturaleza judicial del proceso; se entiende asimismo la opinión de quienes piensan que este atajo sólo debe usarse en casos muy claros, cosa que la misma ley parece decir ${ }^{69}$.

No habiendo todavía suficiente experiencia, la doctrina, conectando la praxis procesal vigente con el nuevo proceso, ha tratado de establecer teóricamente qué capítulos de nulidad podrían ser sustanciados por el proceso breve y cuáles no, por requerir en principio una investigación más compleja de lo que permiten el carácter y los plazos señalados para su instrucción.

Por este camino, se han excluido las causas por incapacidad (c. 1095), salvo que junto con el escrito de demanda se aporten documentos médicos que

da con la demanda haga patente la nulidad» (El nuevo proceso..., cit., 578). Del Pozzo señala como «l'evidenza della nullità non coincide con il semplice fumus boni iuris o la possibile fondatezza della pretesa, implica una convinzione plausibile e positiva. Non si richiede ovviamente la certezza o persuasione circa la nullità, ma la presenza di segnali o indizzi convincenti. La valutazione del Vicario giudiziale si fermerà logicamente a livello di parvenza o impressione... Non si richiede insomma un giudizio preventivo e sommario ma un filtro o vaglio prudente e attendibile» (Il processo matrimoniale più breve..., cit., 137). Por su parte Ebed-Melek se pregunta «pourquoi charger l'instructeur de recueillir les preuves (canon réformé 1686) alors que le dossier est censé avoir pu être suffisamment étudié auparavant par les enquêteurs et par le vicaire judiciaire pour que ce dernier ait été capable de décider que la cause suivra la procédure brève! Comment pouvoir prendre cette décision sans avoir eu en mains non seulement une indication des éléments de preuve... mais ces éléments eux-mêmes!» (Breves remarques..., cit., F).

${ }^{67}$ No faltan ejemplos de formalismo en el juicio de admisibilidad, por ej. ante la Corte Europea de Derechos Humanos donde con frecuencia se deciden en la misma sentencia la admisibilidad y el fondo de la querella.

${ }^{68}$ En realidad los requisitos o cualidades que el c. 1684 impone a la demanda de proceso más breve podrían extenderse a todos los casos, combinando los cc. 1676 y 1684, de modo que el Vicario al examinar cualquier escrito de demanda juzgue la posibilidad de que se cumplan las circunstancias del c. 1683 e intente sea completado en los términos del art. 15 de las RP, de modo que pueda decidir la sustanciación de la causa según el rito más breve y sugerir al Obispo avocar su tramitación o al menos la decisión.

${ }^{69}$ Vid. las extensas reflexiones de C. M. Morán Bustos, El proceso «brevior»..., cit. 
«pueden hacer inútil adquirir una pericia de oficio» $(\mathrm{RP} \text { art. } 14 \$ 2)^{70}$; también se puede pensar en circunstancias de hecho o documentos de otro tipo que -independientemente de los documentos clínicos- hagan inútil la pericia (condenas por violencia, alcoholismo, drogadicción, ludopatía ${ }^{71}$.

También hay autores que de entrada excluyen otros vicios o defectos de consentimiento, en cuanto su gestación íntima hace su prueba más compleja y delicada de lo que permite la instrucción del brevior.

Con todo, se observa que si la reforma del Mitis Iudex se propone simplificar y agilizar los procesos matrimoniales ${ }^{72}$, y es opinión común que a tal efecto responde la novedad del proceso breve, sería una paradoja que luego esta vía quedase reservada a pocos casos y estuviera vedada para tratar los motivos de nulidad que se aducen con mayor frecuencia. La ley reserva este proceso a casos de nulidad evidente, pero la preclusión a priori de determinados capítulos no parece adecuada, considero con Ferrer «que cualquier causa de nulidad puede ser objeto del proceso abreviado, porque lo importante no es la causa en sí, sino los indicios de prueba existentes» ${ }^{73}$; lo propio será pues atisbar al menos esa evidencia caso por caso, a partir del escrito de demanda y sus anejos: aunque todavía escasos, los datos parecen apuntar que se están tratando por la vía breve todos los capítulos de nulidad. Las circunstancias enumeradas en el la Ratio procedendi, art. $14 \$ 1$ no parecen excluir a priori ningún motivo de nulidad, mientras que el $\$ 2$ del mismo art. podría interpretarse en el sentido de excluir las causas de incapacidad que requieran el recurso a la pericia.

\section{La instrucción}

La decisión del Vicario de que se siga el proceso más breve afecta, como dije, a la instrucción; pues a más de formular el dubium puede designarse a sí

${ }^{70}$ Entiendo por tales diagnósticos y pronósticos, informes o tratamientos que demuestren la incapacidad; no creo en cambio que lo sean los exámenes, informes o pericias realizados con miras al proceso (p.e. durante la investigación prejudicial). Parece lógico que sea el Vicario, quien a la vista de los documentos presentados decida a la vez la suficiencia de los mismos y la tramitación o no de la instancia por el rito abreviado.

${ }^{71}$ El caso es que se tramitan por esta vía causas de incapacidad, aunque desconozco las circunstancias en que son admitidas. Tal vez, en casos, sería posible realizar una buena pericia de oficio en los 30 días de 'plazo' para la sesión única; pero a menos que concurran otros elementos parece que se trataría de la reducción ad breviorem de un proceso normal.

72 Proemio.

73 J. FERRER ORTIZ, Valoración de las circunstancias que pueden dar lugar al proceso abreviado, Ius Canonicum 56 (2016), 167. 
mismo como instructor de la causa; en todo caso le compete nombrar al instructor y al asesor, decidir quiénes deben participar en ella: en definitiva qué pruebas se podrán intentar y el momento o momentos en que deben realizarse.

Siguiendo el surco del contencioso oral se propone aquí también, salvadas las distancias, la recogida de las pruebas «en lo posible en una sesión» (c. 1686).

La idea me parece peregrina e ingenua, incluso aunque se tratara de una precisión ulterior del concepto probationes quae statim a iudice colligi possint del c. $1684,2^{\circ}$, entendiendo por éstas aquellas que el Vicario estime posible realizar en la sesión ante el instructor, en la cual se supone con no poco optimismo que estarán presentes todos los que el Vicario haya decidido, con base en la demanda, «que deben participar» (c. 1685). Parece desconocerse la dificultad que entraña reunir a varias personas, por lo menos en ciudades de cierto tamaño como suelen ser las sedes episcopales; la experiencia autoriza a preveer un alto número de ausencias y deserciones.

Tal como se leen, los cánones de este proceso no dejan espacio a la proposición de pruebas; no ya a las partes que necesariamente han de estar de acuerdo en los términos de la petición ${ }^{74} \mathrm{y}$ habrán propuesto las pruebas oportunas $^{75}$, sino al Defensor del vínculo que se supone es la parte procesal llamada a objetar en juicio la nulidad demandada, cuya intervención en la instrucción parece reducirse a proponer puntos para el interrogatorio de partes y testigos (RP art. 17). Ciertamente, recibida la demanda y al ser oído in limine (c. $1676 \$ \$ 1$ y 2), habrá podido sugerir al Vicario la actuación de ciertas pruebas; pero no parece que pueda proponerlas en forma ni exigir que se realicen,

${ }^{74}$ Aunque quepan matices, discrepo en principio de los posibilismos interpretativos del inciso del c. $1683,1^{\circ}$ «con el consentimiento del otro», pues no creo que se pueda presumir y menos suplir. En este sentido, C. PEÑA, El nuevo proceso..., cit., 576-577; quien sin embargo considera que en algunos casos podría haberse admitido la conformidad tácita de la otra parte (ibid., 579). M. J. ARROBa CONDE, considera que el acuerdo de las partes incluye no sólo la ratio petendi sino que deben ser «concordi sui fatti storici posti a fondamento del motivo di nullità, in modalità tale da assicurare una versione concorde e coerente» (Le «Litterae motu proprio»..., cit., 566); asimismo P. Moneta estima que el consentimiento debe ser claro y seguro (La dinamica processuale..., cit., 46-49).

${ }^{75} \mathrm{La}$ iniciativa que se atribuye al Vicario sobre la instrucción, por cuanto deseable, debe compadecerse con el derecho a la acción de los interesados que incluye sea los motivos de pedir que la proposición de pruebas; aunque podría entenderse que, en aras de la celeridad, renuncian momentáneamente a esta facultad, que recuperan íntegra si la causa es deferida a la vía ordinaria. A. Zambon, considera que si no bastan las pruebas aportadas con la demanda, o a lo sumo hasta los tres días anteriores a la sesión única, se debería ir a la vía ordinaria (Il motu proprio Mitis Iudex Dominus Iesus. Prima presentazione, http://www.ascait.org/sites/default/files/MID_Presentazione_2015-11-09\%20(1).pdf). 
y menos a la vista de lo actuado en la sessio una. Así las cosas, cabe preguntarse por la naturaleza del proceso.

En todo caso, tan drástica simplificación del procedimiento estará en proporción a la facilidad de adquisición de pruebas y a la contundencia de éstas en favor de la nulidad; asimismo, la brevedad y estrechez del periodo instructorio deberían ser compensadas por la intensidad y profundidad de la instrucción, lo que requiere prepararación, experiencia y seriedad en el instructor, que debe gozar de la autonomía suficiente para realizar eficazmente tan delicada labor; por lo que no debe ser considerado un mero ejecutor del mandato recibido del Vicario; aunque parezca haber razones para sostenerlo, su misión no debería ceñirse a recoger solamente aquellas pruebas que el Vicario haya establecido como de inmediata adquisición por demás, a ser posible, en una sola sesión (c. $1684,2^{\circ}$ ).

No se me alcanza por qué no puede ir recogiendo las pruebas (no sólo documentos, sino testimonios y declaraciones) dentro del término que va del decreto de litis contestatio c. $1685^{76}$ hasta el momento de la unica sessio, incluidas aquellas de cuya existencia haya tenido noticia mientras tanto, siempre en lo posible en el término de 30 días señalado. Para esto sería suficiente que tenga mandato bastante a tenor del c. $1428 \$ 3$.

Del Pozzo la califica la sessio una de concentración instructoria, viendo en esa «il chiaro intento di procedere alla raccolta possibilmente in un'unica udienza e comunque in un arco temporale molto ristretto» de todas las pruebas ${ }^{77}$. No le falta optimismo al estimar que la concomitancia de cónyuges (y testigos) en esa única sesión «garantisce non solo la dichiarazione di entrambe le parti ma l'eventuale riscontro incrociato (in caso di contraddizioni o di-

76 Tratando tal vez de superar un formalismo con otro de nueva generación, parece correcto decir que en los procesos de nulidad no hay objeto litigioso sino un hecho a demostrar sobre el que los cónyuges pueden o no estar de acuerdo. Es claro que si fuera así tampoco habría confesión proprie dicta. Pero lo es también que contra la presunción legal de validez, el actor tiene interés y pide una declaración de nulidad, no de mera ciencia ni simplemente de verdad. Ésta desde luego es importante, como base de la nulidad a declarar, pero no es el objeto principal del proceso ni el objetivo del actor, quien desea que $s u$ verdad (o persuasión) sea la verdad y por eso acciona, y el demandado la suya cuando quiere se afirme non constare. El proceso será todo lo institucional que se quiera pero no es un equipo de investigación dirigido por el juez ni mucho menos. Podrán todos contribuir a la verdad si contribuyen, pero cada cual propone la suya y dice hela aquí o está allí. Suele citarse a este propósito el Discurso de Pío XII a la Rota del año 1944 [AAS (1944) 281290, también en btcaah], que es moral, no dogmático o metafísico, ni se debe confundir el finis operis con el operantis, ni honradez con imparcialidad, aunque no se opongan necesariamente.

77 M. DEL Pozzo, Il processo matrimoniale più breve davanti al Vescovo, Edusc, Roma 2016, 171. 
vergenze) e le tempestive integrazioni o chiarimenti. Anche le testimonianze possono quindi giovarsi della contestualità e degli apporti degli astanti... sono in grado di incentivare il valore e l'efficacia dei dati raccolti» (ibid.) y añade en nota que «in base al principio di economicità globale dell'azione il "tutti, tutto e subito" permette di fare le cose prima, meglio e più armonicamente» ${ }^{78}$.

Aun cuando sucediera efectivamente así (puede igualmente suceder lo contrario: depende de en qué términos se produjera la ruptura), el hecho de que se haya separado la instrucción de la decisión (a diferencia del proceso oral), y entre ambas tenga que mediar una verbalización sintética (RP art. 18 $\$ 2$ ), hace que toda la eventual riqueza y vivacidad de esta nueva forma de instrucción se quede en el instructor, pero no pase al decidente de modo inmediato; otra cosa es el relato que el mismo instructor pueda luego hacer al Obispo cuando lo consulte.

No es difícil imaginarse una instrucción judicial ideal con todos los interesados presentes o a disposición del instructor, realizada en una única sesión dirigida por él, con varias audiencias en la que intervienen sucesivamente las partes, los testigos, los técnicos, etc. Pero resulta más difícil pensar en una suerte de mesa redonda a la que llegan y en la que se enfrentan las partes y los testigos. Cuando menos no creo que de ello pueda resultar más claridad y certeza transmisibles al obispo en breve síntesis.

\section{Proceso Más BREVE y deClaración de LaS PaRTES}

De la confesión y las declaraciones de las partes se ocupa el c. $1678 \$ 1$ en el contexto general de los procesos de nulidad de matrimonio, pero los cánones que pergeñan el proceso más breve no se refieren a ellas en particular. En teoría no es en este proceso donde las declaraciones de las partes deberían tener mayor protagonismo, visto que uno de los requisitos para tratar una demanda por esa vía breve es que concurran en ella circunstancias de hecho o de personas, apoyadas en testimonios y documentos, que sin mayores indagaciones o detalles hagan manifiesta la nulidad (c. $\left.1683,2^{\circ}\right)^{79}$. Las pruebas de esas cir-

78 Ibid., nota 10.

${ }^{79}$ Parece incuestionable que ni la evidencia de la nulidad ni la inmediata disponibilidad de las pruebas pueden deducirse a su vez de la mera las declaración de las partes; «rimane quindi escluso che possa essere considerata come prova adeguata a consentire l'adozione del processo breve la sola dichiarazione delle parti» (P. MONETA, La dinamica processuale..., cit., 52). 
cunstancias serán accesibles inmediatamente al juez (instructor) y los documentos irán adjuntos al libelo (c. $1684,2^{\circ}$ ), el cual es a la vez petición, declaración y alegato, indicación y aportación de pruebas.

Con todo, se intuye que muchas vece esas pruebas inmediatas resultarán en buena parte del requisito de litisconsorcio activo, que se manifestará en las declaraciones sustancialmente concordes de las partes, prueba que por definición entrará en la instrucción de los procesos breves, y que será el vehículo más apto para apurar efectivamente la realidad y alcance de esa concordia ${ }^{80}$.

Y cabe preveer que dadas las la celeridad y las reducidas posibilidades indagatorias que la ley pretende para estos procesos, esas deposiciones tendrán un valor importante; por lo pronto para corroborar y explicar con más detalle esa exposición breve, íntegra y clara de los hechos que debe contener la demanda escrita (cfr. c. $1684,1^{\circ}$ ).

De la proposición concorde de la causa se desprende que ambas partes sean examinadas por el instructor en la sesión prevista. No hay desde luego ninguna norma que lo imponga expresamente, ni podría, pero es lógico entender incluidas a las partes entre «todos aquellos que deben participar», a quienes debe citar el Vicario según el c. 1685. El conocimiento preliminar de que una de las partes no participará activamente (aunque consienta en la acción), creo sería motivo para disuadir al Vicario de elegir el proceso breve, salvo fuerte evidencia contraria.

Con todo, la ausencia de una parte de la sesión probatoria no supone necesariamente que deba renunciarse al proceso breve. Sin duda debilita las razones para su uso, pero depende de qué parte se trate y de la causa petendi. Es más -digamos- llevadera la ausencia de la parte que se limitó a consentir en la demanda de la otra y no está mayormente implicada en el motivo de la nulidad, ni en su demostración; aunque, como dice Del Pozzo, empaña no poco el supuesto interés conjunto en la nulidad y sus motivos; y la justificación de las menores garantías que comporta este proceso $^{81}$. La ausencia en cambio

${ }^{80}$ «Il contenuto della fase probatoria nel processo abbreviato... sarà costituita (rectius costituito) prevalentemente dalle deposizioni. L'assistenza dei coniugi garantisce non solo la dichiarazione di entrambe le parti ma l'eventuale riscontro incrociato (in caso di contraddizioni o divergenze) e le tempestive integrazioni o chiarimenti» (M. DEL Pozzo, Il processo matrimoniale più breve..., cit., 171).

${ }^{81}$ Según las circunstancias se podría dudar que se haya constituido parte cuando en realidad se ausenta del proceso, p.e. si se hubiera limitado a firmar la demanda sin siquiera conocer bien su contenido. 
de quien tomó la iniciativa y pidió la prosecución de la causa según el rito abreviado, compromete ulteriormente las ya escasas posibilidades de obtener pruebas suficientes para acoger la demanda con la certeza requerida, y la misma naturaleza del procedimiento.

Como ya se ha dicho la calidad de la instrucción es la única posibilidad para una decisión justa. Por la estrechez de tiempo y la limitación de pruebas, el instructor debe esmerarse en todo lo referente a la sesión única y dentro de ésta a la audiencia de las partes.

Las condiciones en que ésta se realiza en el processus brevior requieren, en primer lugar del Vicario pero luego del instructor, una competencia jurídica y humana notables. Como dice Bianchi aunque la norma no exija particulares títulos académicos y baste una preparación humanística, el buen cumplimiento de los cometidos que se asignan al instructor y al asesor, hace muy aconsejable la adecuada competencia jurídica de ambos ${ }^{82}$. Arroba Conde da por supuesto que son «tecnici, con i quali il Vescovo è obbligato a consultarsi prima di decidere: l'Istruttore e l'Assessore» ${ }^{83}$.

Teniendo en cuenta los datos de la eventual investigación pastoral o prejudicial (RP arts. 2-5) vertidos en el proceso ${ }^{84}$, el instructor debe aparejar la audiencia de las partes con esmero, identificando bien los hechos relevantes a partir del escrito de demanda y los documentos anejos; preparando las preguntas y las posibles réplicas de manera que en lo posible se despejen dudas, se aclaren incoherencias, se precisen detalles, se complete el cuadro del asunto $^{85}$. Todas las partes pueden proponer las cuestiones sobre las que deseen verse el interrogatorio, pero toca al instructor hacerlas propias, integrarlas en el conjunto y formular concretamente las preguntas de modo que sean pertinentes y adecuadas (cfr. cc. 1534, 1564). Para lo cual, con la deli-

82 P. BIANCHI, Lo svolgimento del processo breve: la fase istruttoria e di discussione della causa, en REDAZIONE DI QUADERNI DI DIRITTO ECCLESIALE (a cura di), La riforma dei processi matrimoniali di Papa Francesco, Ancora, Milano 2016, 69-70.

${ }^{83}$ M. J. ARRoba Conde, Le «Litterae motu proprio»..., cit., 566, cfr. 569, nota 56. Parece atribuir a esta consulta un efecto sanador de la eventual impericia del Obispo.

${ }^{84}$ Sobre la naturaleza de esta investigación y los problemas que suscita, C. M. FABRIS, Indagine pregiudiziale o indagine pastorale nel Motu proprio Mitis Iudex Dominus Iesus. Novità normative e profili problematici, Ius Ecclesiae 28 (2016) 479-503.

85 «Per esempio, -continúa Bianchi- alle parti potranno essere chieste precisazioni su fatti storici di importanza indiziaria per la causa, oppure chiarimenti sul punto di causa, come l'esatto momento della formazione di una intenzione contraria a una proprietà o a un elemento essenziale del matrimonio...» (ibid., 75). 
cadeza de quien sabe estar revolviendo en los protagonistas recuerdos seguramente dolorosos, no se limite a someterlos a cuestionarios elaborados por otros, ni se contente de contestaciones generales o vagas, sino trate de establecer las circunstancias de personas, lugares, momentos, etc.; esto requiere iniciativa y autoridad, de manera que el interrogatorio trascurra ordenadamente, sea esclarecedor y resulte lo más viva posible la reconstrucción de los hechos.

Concretamente la declaración de las partes no puede limitarse a la confirmación, en forma de interrogatorio, de cuanto ya afirmado en la demanda: sería un remedo de instrucción incapaz de esconder la deriva hacia un expediente de jurisdicción voluntaria. Se trata más bien de apurar, a partir del material ya adquirido, aquellos puntos que puedan conducir a una decisión justa y ponderada. Característica peculiar de este proceso es que las partes puedan asistir al examen de las otras y de los testigos, salvo que las circunstancias aconsejen al instructor otro proceder (RP art. $18 \$ 1$ ). Con estas premisas, el instructor deberá sopesar en cada caso si es adecuado o no que cada parte asista al examen de la otra. En principio no lo considero oportuno; no ya por la posible colusión sino por el riesgo de que debiendo interrogar a una parte en presencia de la otra, alguna de ellas se cohíba, se inhiba o se limite a confirmar sin más detalles lo que haya oído decir antes a la otra, eludiendo de este modo la interpelación directa y perdiéndose la oportunidad de contrastar siquiera mínimamente las versiones de ambas. Si fuera necesario siempre podrá carearlas a la vista de las respuestas que hayan dado por separado.

Entre los datos subjetivos importantes a recabar de cada parte dos me parecen importantes. Uno sería en qué modo y ocasión le surgió la duda sobre la validez o llegó a la persuasión de la nulidad de su matrimonio: situación personal, sucesos, encuentros y reflexiones que le condujeron a esas conclusiones. $\mathrm{El}$ otro son los motivos que le han empujado a pedir la nulidad. El instructor debe tratar de apurar si sólo busca aclarar y tranquilizar su conciencia, si obra también empujada por el deseo de contraer nuevas nupcias canónicas, o si el que más bien tiene interés en aclarar la situación y su conciencia es el tercero con quien ahora mantiene el actor una relación afectiva, o los parientes de éste o de ambos; si la prosecución o la interrupción de esta relación depende del resultado del juicio, etc., aparte posibles repercusiones económicas. Si se ha llevado a cabo la investigación prejudicial o pastoral es probable que se tenga noticia de alguno de estos datos, se trata de adquirirlos en el proceso, si es necesario con mayor detalle. 


\section{Verbalización y autos}

La declaración de las partes, como cualquier otra declaración procesal, debe verterse en autos sumariamente pero con la precisión necesaria para que pueda servir a la decisión del juez; tarea en la que instructor y notario colaborarán cada cual según su oficio (RP $18 \$ 2)$. Como dice Del Pozzo, «il testo delle dichiarazioni, come riferito, deve essere succintamente ma esaurientemente verbalizzato» ${ }^{86}$.

Entiendo que una diferencia principal entre un sumario judicial y un expediente administrativo es precisamente la viveza del uno frente a lo descarnado del otro. Una causa matrimonial es una infeliz andanza humana, para decidir la cual el juez debe enfrentarse con personas concretas de determinada condición, temperamento, personalidad y entorno, que suelen ser decisivos en relación al motivo de nulidad aducido. Mantener su naturaleza judicial en verdad, más allá de las palabras, requiere hacer lo posible para que la causa llegue viva al Obispo que la juzga. La pertinencia y resumen de las respuestas (de las partes y de los testigos) no debería eliminar su naturaleza de respuestas, esto es contestaciones a preguntas incisivas, adherentes al escenario del caso ${ }^{87}$.

\section{Circunstancias que pueden permitir el proceso más breve y declaración} de las partes (RP art. 14 \$ 1 )

La declaración de las partes pueden tener una particular relevancia en la apreciación de alguna de las circunstancias indicadas en el art. $14 \$ 1$ de las RP.

La enumeración es ejemplificativa y heterogénea, lo que ha hecho temer (o desear) a más de uno que se estuvieran constituyendo nuevos capítulos de nulidad, más o menos conectados con los existentes ${ }^{88}$. No parece que sea así. Saliendo al paso de las varias perplejidades el Sussidio applicativo explica que «queste circostanze di fatto non sono nuovi capi di nullità», se trata más bien «di situazioni che la giurisprudenza ha da tempo enucleato come elementi sintomatici di invalidità del consenso nuziale, che possono essere facilmente comprovate

${ }^{86}$ Il processo matrimoniale..., cit., 179-180.

${ }^{87}$ La RP $18 \$ 2$ representa un ideal de sumarización que no sé si es compatible con que no se pretenda mayor preparación jurídica a quienes están llamados a realizarla.

${ }^{88}$ Se ha ocupado ampliamente M. ALENDA, ¿Nuevas causas de nulidad matrimonial canónica? El sentido del art. 14 \$ 1 de las reglas de procedimiento contenidas en la Carta Apostólica Mitis Iudex Dominus Iesus, RGDCDEE 40 (2016) 59 pp. 
da testimonianze o documenti di pronta reperibilità. Esse possono presentare, in certi casi, una tale valenza fattuale da suggerire con evidenza la nullità del matrimonio» ${ }^{89}$. Tampoco son presunciones legales, al menos no todas. Su utilidad puede variar mucho según las demás circunstancias de cada caso: tiempo transcurrido, litigiosidad entre las partes pasada y presente, etc. En general, por uno u otro motivo, no han sido bien acogidas por la doctrina ${ }^{90}$.

El problema es que el c. $1683,2^{\circ}$ habla de circunstancias de fácil e inmediata demostración que hagan manifiesta la nulidad, mientras el art. 14 RP citado habla también de circunstancias en presencia de las cuales se puede proceder por el rito más breve. ¿Son las mismas? ${ }^{91}$ La cosa dista de ser lineal y complica aún más la de por sí confusa consecutio temporum -por así decir- del proceso brevior, donde en aras de la rapidez han desaparecido los tiempos técnicos ${ }^{92}$. A mi en-

89 Tribunale Apostolico Della Rota Romana, Sussidio applicativo del Motu pr. Mitis Iudex Dominus Iesus, Città del Vaticano, gennaio 2016, 32, cursiva original. Cito como se suele este documento, de autoría y valor inciertos, que se atribuye de hecho a la Rota Romana.

90 Entre otros E. PETERS, A second look at Mitis, especially at the new fast-track annulment process, Blog: In the Light of the Law; M. DEL Pozzo, Il processo matrimoniale..., cit., 139; J. FerRer ORTIZ, Valoración de las circunstancias..., cit.; G. BONI, La recente riforma..., cit., (parte seconda) 15-19.

91 A. Bunge, parece estimarlo así cuando al hablar de las circunstancias del c. 1286, $2^{\circ}$ (que hacen evidente la nulidad) comenta «será normalmente la investigación pastoral o prejudicial de la que se habló antes, la que permitirá identificar estas circunstancias, de las que las Reglas de procedimiento nos presentan un elenco indicativo (cfr. Reglas de procedimiento, art. $14 \$ 1$.)», y poco más adelante advierte «que ninguna de ellas por sí misma es indicación suficiente de la posibilidad de aplicar el proceso más breve ante el Obispo, sino sólo en tanto y en cuanto hagan efectivamente evidente la nulidad, que puede demostrarse con testimonios o pruebas documentales de inmediata adquisición. Es entonces, la evidencia de la nulidad y la facilidad de su prueba, además del consentimiento de ambas partes, la que permite la aplicación del proceso más breve ante el Obispo». (Presentación del nuevo proceso matrimonial, conferencia, 11 noviembre 2015, publicada online en http://www.awbunge.com.ar/Nuevo-Proceso-Matrimonial.pdf, p. 17). Pero si la nulidad es evidente es porque ya está probada, no que sea fácil de probar: caso en el cual al Obispo corresponde confirmar y sentenciar con su autoridad lo que el Vicario ha juzgado evidente in limine. En esta dinámica surge de nuevo el interrogante sobre la utilidad de la instrucción.

92 Una conjetura de secuencia es la que expongo esquemáticamente a continuación: 1) Las partes en alguno de los modos previstos describen detalladamente su caso en la demanda y afirman que concurren circunstancias (las que enumera RP art. 14 u otras) que hacen evidente la nulidad (algo que casi siempre afirma el demandante). 2) Otrosí dicen que esos hechos son de tal forma fácil y velozmente demostrables, con documentos (que aportan) y testimonios (que indican), que no hace falta una indagación más larga y precisa. 3) El Vicario a la vista del escrito de demanda, de los documentos y demás propuestas de prueba aportados, juzga si es probable que sea así y decide si se debe seguir el rito abreviado o no. 4) Si la decisión es positiva se procede a la instrucción en los términos del decreto de los cc. $1676 \$ 2$ y 1685 , o sea limitada en los plazos y en las garantías procesales. 5) Con los resultados obtenidos el Obispo declara la nulidad o bien defiere la causa al proceso ordinario. Según esta interpretación, el proceso brevior podría intentarse en muchos casos: aunque la defensa del vínculo no parece bien garantizada, la evidencia liminar y la certeza que se exigen podrían suplir esta tara, aparte la eventual apelación. 
tender se trata de circunstancias que, si se demuestran (y en casos esto será fácil), podrían hacer manifiesta la nulidad o al menos ser serio indicio de ella ${ }^{93}$; mas no siempre ni por sí solas, por lo que habrá que distinguir bien la presencia y prueba de alguna o más de estas circunstancias y la presencia y prueba del motivo o motivos de nulidad invocados (c. $1676 \$ 5$ ); con todo hay que reconocer que en ciertos casos habrá una relación bastante directa entre ambas cosas.

En otros casos sólo estaremos ante un desplazamiento del problema, que ahora se situa en una circunstancia anterior, que hay que demostrar y podría ser indicio del capítulo de nulidad invocado.

En verdad parece que lo que el legislador ha querido decir es que si en la investigación prejudicial o pastoral (RP arts. 2-5) aparece clara (demostrada o casi) alguna de las circunstancias que enumeran la Reglas procesales (art. 14), se puede en principio recurrir al proceso brevior; si bien depende de cuál de esas circunstancias se trate pues son muy distintas unas de otras. $\mathrm{Y}$ siguiendo el recorrido lógico sería más convincente poner esas circunstancias, cuando aparecen en la investigación previa, no tanto en relación con el c. $1683,2^{\circ}$ cuanto con el c. 1684, es decir con el escrito de demanda.

A nosotros nos interesa el valor que la declaración de las partes puede tener en relación con estas circunstancias, por lo que nos detendremos brevemente en cada una de ellas.

Así, la falta de fe (quid probandum) «que puede generar simulación»o error determinante, podría ser fácil de demostrar en base a las declaraciones de las partes corroboradas por testimonios, testigos y otras pruebas inmediatas (p. e. no haber hecho la primera comunión, ni estar confirmado, no haber cursado religión en el colegio, etc.). Estas circunstancias tal vez fáciles de constatar, serían a su vez prueba de la circunstancia (la falta de fe) que se considera fácil de demostrar (sin una instrucción más honda) y que permitiría el recurso al breviore porque podría dar lugar a simulación o error. Pero de posse ad esse non valet illatio, por lo cual la falta de fe (a demostrar) no hace manifiesta ni siquiera una causa simulandi próxima grave y menos la simulación que podría haber ocasionado, pero que no necesariamente causa: en realidad sería

93 J. Ferrer Ortiz, siguiendo el Sussidio applicativo (p. 32), considera las circunstancias del art. 14 RP ejemplo de las que hacen manifiesta la nulidad del c. $1683,2^{\circ}$; pero concluye que tanto el art. 14 $\mathrm{RP}$ como el Sussidio son 'soluciones' que crean más problemas de los que tratan de resolver ( $\mathrm{Va}$ loración de las circunstancias..., cit., 160 y 167). En el mismo sentido R. ROdRÍGUEZ-OCAÑa, Comentario al c. 1683, en AA. Vv., Código de Derecho Canónico. Edición anotada (Addenda), Eunsa, Pamplona 2016. 
sólo un indicio, cuyo influjo en el consentimiento hay que indagar ${ }^{94}$ : no es manifiesto; porque la falta de fe puede significar desde ausencia de práctica o increencia respetuosa a oposición o rechazo explícito o incluso hostil.

$\mathrm{Al}$ examinar a las partes, el instructor procurará por tanto ir más allá del simple 'no creía', 'no practicaba' o 'no quería saber nada', para averiguar las actitudes y manifestaciones habituales de esas negaciones; por ejemplo: si alguna vez acompañaba a la otra parte a algún acto religioso, cómo fue que aceptó casarse por la Iglesia, cómo siguió la catequesis preparatoria, etc. Si se trata de un no católico habría que indagar cómo acogió las cautelas, licencias o dispensas relativas al caso.

La brevedad de la convivencia, fácil de probar, es siempre un indicio fuerte de que algo no andaba bien desde antes, pero no causa de nulidad. La doctrina se pone la cuestión de lo que deba entenderse por brevedad, cosa que debe estimar el Vicario, no todo tiene que estar reglado ${ }^{95}$. La declaración de las partes servirá para apurar los motivos tanto de la boda como de esa rápida crisis, su antecedencia y eventual incidencia en el consentimiento (incapacidad, dolo, error en cualidad, etc.); se trata aquí de conocer objetivamente la veloz evolución hacia la ruptura más que de atribuir culpas, por lo que parece aconsejable el examen separado de las partes.

De fácil e inmediata demostración es asimismo el aborto, que obviamente se provoca para impedir el nacimiento de un hijo en ciernes. Habrá que interpretar el para impedir la procreación como 'signo de la exclusión de la prole' (caput nullitatis), lo cual no siempre corresponde: hay que demostrar en juicio la intención simuladora antenupcial, que el recurso al aborto no hace evidente. La declaración de cada parte habrá de esclarecer p.e. la aversio prolis no sobrevenida y sus causas, constancia en el uso de medios anticonceptivos, reacción ante la noticia del embarazo, iniciativa y propuesta, motivos y decisión de abortar, medios usados, etc.; asimismo confrontarse con los demás elementos de prueba, en concreto con declaraciones extrajudiciales que den a conocer la actitud inicial de las partes en relación a la eventual descendencia.

\footnotetext{
${ }^{94}$ A menos que se considere la falta de fe como causa en sí de nulidad en ciertas circunstancias; el Discurso del Papa a la Rota de 2017 (btcah) pone en relación verdad, amor y fe, subrayando como su carencia, cultural y personal, pueden influir en la celebración de un válido matrimonio. Pero esto no es lo que dicen las Reglas Procesales de que nos estamos ocupando.

95 M. AlENDA, ¿Nuevas causas de nulidad..., cit., 17-23.
} 
La obstinada permanencia en una relación extraconyugal al tiempo de la celebración manifiesta (es en sî) claramente una exclusión del bonum fidei, superada la pretensión de que ésta exista sólo si el simulador se reserva un verdadero $i u s^{96}$. Lo que no parece inmediato es su fácil demostración en todo caso; el examen atento de las partes, especialmente la llamada confesión, en sí suspecta, puede ser un medio importante para verificar la existencia y pervicacia de una infidelidad no episódica en torno al periodo nupcial. Se atisba aquí la particular, novedosa formulación legal de un supuesto de exclusión del bonum fidei $i^{97}$.

No sucede igual con las varias circunstancias cuya ocultación intencional sería indicio de nulidad por dolo. La Regla procesal enumera a mi entender circunstancias fácilmente demostrables, objetivamente susceptibles de perturbar la vida conyugal gravemente, que podrían también explicar la brevedad de la vida conyugal; pero que no constituyen motivos de nulidad diferentes al dolo definido en el c. 1098, pues entiendo que no se intenta aquí de ampliar ese capítulo de nulidad abandonando la distinción entre casarse con dolo y por dolo. Esa ocultación, que la RP parece atribuir a una de las partes en daño de la otra (y no a tercero), además de ser dolosa, debe reunir las otras características de este supuesto legal: intención, finalidad, eficacia. La declaración judicial de las partes, tanto de la reticente como de la que sufrió el engaño, será medio de prueba imprescindible para apreciar esos elementos, así como la reacción de ésta tras descubrirse engañada, la eventual demora entre ese descubrimiento y la introducción de la causa, etc. En estos casos parece aconsejable el examen separado de las partes.

El haberse casado por un embarazo imprevisto o por una razón totalmente ajena a la vida conyugal puede ser ciertamente indicio de insuficiencia del consentimiento, que habrá de ponerse en evidencia en alguna de sus formas previstas: inmadurez, simulación, falta de discreción; pero no dice de por sí relación a una causa de nulidad concreta, ni lo es en sí según el derecho positivo ${ }^{98}$; además puede adquirir matices culturales notables. $\mathrm{Al}$ apreciar la concurrencia de estas circunstancias el Vicario habrá ya decidido, a partir de la demanda, el caput concreto del cual son manifestación. Se entiende que se trata del

96 Ibid., 31-32.

97 Relevante a mi juicio, aunque no se trate aún de un capítulo de nulidad autónomo.

98 Entiendo que, como la fe, un mínimo de afectio coniugalis se requiere para contraer válido matrimonio y quizá esta circunstancia apunta a ello: cfr. nota 94. 
motivo principal y prevalente de las nupcias, pues a la formación del consentimiento concurren diferentes motivaciones que no se excluyen entre sí. Es sabido p. ej. que el embarazo -imprevisto, desde luego- puede motivar la anticipación responsable y consciente de la boda a la que ya estaba orientada la relación, para dar al nasciturus una familia regular, o puede acontecer en el seno de una convivencia more uxorio. Aparece evidente la importancia y delicadeza de la labor del instructor al examinar a las partes, tratándose como se trata de un elemento subjetivo del consentimiento (finis operantis).

En muchos casos la violencia física sólo podrá ser acusada por la víctima, tal vez 'confesada' por el agresor; entiendo aquí no ya la violencia durante la boda (pues sería evidente que no hubo tal), sino a la ejercida por así decir como causa contrabendi, para convencer-obligar a uno casarse, no con amenazas sino por vías de hecho. Ha de indagar el instructor en este caso sobre el momento, el modo, duración, efectos, la reacción del que la padeció cuando se sintió seguro, etc. A su vez es difícil que no haya dejado secuelas exteriores: trazas corporales visibles, auxilios médicos, denuncias después retiradas, desahogos con íntimos, etc.; que podrían servir para corroborar la deposición de las partes.

\section{CONCLusión}

La declaración de las partes es desde siempre un elemento importante del que raramente se puede prescindir en la instrucción procesal, particularmente de las causas matrimoniales, en las que siempre se entremezclan elementos subjetivos e íntimos que sólo el protagonista puede desvelar. Su calidad de prueba, afirmada legalmente a partir del CIC en vigor, se ha venido a añadir a su relevancia para la adquisición procesal de hechos pertinentes para la decisión. De otra parte, el interés que obviamente las mismas partes tienen en la causa requiere un especial esmero en la preparación y desarrollo de su examen judicial por parte del instructor. Esto se hace aún más perentorio en el processus brevior, donde las garantías procesales (de las partes y del interés eclesial) se ven drásticamente comprimidas en aras de la evidencia de una nulidad, que se considera a priori fácil y velozmente demostrable.

Si los medios que esta reforma del proceso matrimonial ha dispuesto para imprimir a éste mayor celeridad y proximidad institucional sean además aptos para dirimir las causas conforme a verdad y justicia, es algo que la experiencia irá revelando, sugiriendo al tiempo las posibles oportunas rectificaciones y mejoras de un sistema tan novedoso. 
El autor de estas líneas tiene la impresión que lo que el MP Mitis Iudex ha introducido no es una reforma: ha abierto un proceso de revisión de los juicios matrimoniales dentro del amplio panorama de la pastoral familiar, que exige ir más allá de los interrogantes y disquisiciones sobre los flecos técnicos que han podido quedar sueltos, para preguntarse sobre el papel y la utilidad que puede tener un diagnóstico jurídico sobre matrimonios muertos. Tal vez se trate más de procurar que nazcan y vivan, de prevenir, que no de consolar resolviendo que no nacieron nunca, porque en el fracaso de cualquier unión hay siempre algo que nació y que muere. $\mathrm{O}$ tal vez se trate de asumir que entre matrimonio y familia no existe una relación unívoca, causal y necesaria: nacen cada vez más familias que no están fundadas en el matrimonio legal.

Con todo, estoy convencido de que en este panorama al derecho corresponde un papel tan importante como limitado, que no es otro que el suyo de establecer lo justo en las relaciones humanas dentro de la sociedad, sea para un caso sea para muchos, con las técnicas y método que le son propios. En el caso de la Iglesia, esto ha de procurarse de manera coherente con la doctrina y misión que le han sido confiadas. 


\section{Bibliografía}

Alenda, M., ¿Nuevas causas de nulidad matrimonial canónica? El sentido del art. 14 S 1 de las reglas de procedimiento contenidas en la Carta Apostólica Mitis Iudex Dominus Iesus, RGDCDEE 40 (2016) 59.

ARroba Conde, M. J., Relación entre las pruebas y la comprobación de la verdad en el proceso canónico, Anuario de Derecho Canónico 1 (abril 2012) 11-36.

—, Le «Litterae motu proprio datae» sulla riforma dei Processi di nullità matrimoniale: prima analisi, Apollinaris 88 (2015) 553-570.

BAURA, E., Il valore normativo dell'Istruzione Dignitas Connubii, en P. A. BONET - C. Gullo (cur.), Il giudizio di nullità matrimoniale dopo l'Istruzione «Dignitas Connubii». Parte prima: i principi, LEV, Città del Vaticano 2007, 185211; también en btcais.

BIANCHI, P., Lo svolgimento del processo breve: la fase istruttoria e di discussione della causa, en REDAZIONE DI QUADERNI DI DIRITTO ECCLESIALE (a cura di), La riforma dei processi matrimoniali di Papa Francesco, Ancora, Milano 2016, 6790.

—, Il servizio alla verità nel processo matrimoniale, Ius Canonicum 57 (2017) 83104.

BonI, G., La recente riforma del processo di nullità matrimoniale. Problemi, criticità, dubbi (parte prima), Stato, Chiese e pluralismo confessionale 9/2016 (7 marzo 2016) 1-78 (www.statoechiese.it).

-, La recente riforma del processo di nullità matrimoniale. Problemi, criticità, dub$b i$ (parte seconda), Stato, Chiese e pluralismo confessionale 10/2016 (14 marzo 2016) 1-76 (www.statoechiese.it).

-, La recente riforma del processo di nullità matrimoniale. Problemi, criticità, dubbi (parte terza), Stato, Chiese e pluralismo confessionale 11/2016 (21 marzo 2016) 1-82 (www.statoechiese.it).

Del Amo, L., Interrogatorio y confesión en los juicios matrimoniales, Eunsa, Pamplona 1973, $594 \mathrm{pp}$.

Del Pozzo, M., L'organizzazione giudiziaria ecclesiastica alla luce del m.p. «Mitis iudex», Stato, Chiese e pluralismo confessionale 36/2015 (23 noviembre 2015) 1-33 (www.statoechiese.it).

—, Il processo matrimoniale più breve davanti al Vescovo, Edusc, Roma 2016, 220 pp.

Domingo, R. (dir.), Principios de derecho global, Thomson-Aranzadi, Pamplona 2003, 363 pp. 
Ebed-Melex, Breves remarques sur le Motu Proprio «Mitis Fudex» du Pape François, http://www.verites-catholiques.fr/mitis-judex-commentaireebed-melek/.

FABRIS, C. M., Indagine pregiudiziale o indagine pastorale nel Motu proprio Mitis Iudex Dominus Iesus. Novità normative e profili problematici, Ius Ecclesiae 28 (2016) 479-503.

FERRER ORTIZ, J., Valoración de las circunstancias que pueden dar lugar al proceso abreviado, Ius Canonicum 56 (2016) 157-192.

LLOBELL, J., La genesi dei disposti normativi sul valore probatorio delle dichiarazioni delle parti: il raggiungimento del principio della libera valutazione delle prove, en S. GHERro (cur.), Confessione e dichiarazione delle parti nelle cause canoniche di nullità matrimoniale, CEDAM, Padova 2003, 99-145; también en btcaev.

—, I processi matrimoniali nella Chiesa, Edusc, Roma 2015, 375 pp.

-, Alcune questioni comuni ai tre processi per la dichiarazione di nullità del matrimonio previsti dal M.P. «Mitis Iudex», Ius Ecclesiae 28 (2016) 13-38.

—, El ejercicio personal de la potestad judicial del Obispo diocesano. Algunas consideraciones preliminares al M.P. «Mitis Iudex» y al M.P. «Mitis et Misericors», RGDCDEE 41 (2016) 1-27.

Moneta, P., Processo di nullità, matrimonio e famiglia nell'attuale dibattito sinodale, Stato, Chiese e pluralismo confessionale 8/2015 (7 marzo 2015) 1-19 (www.statoechiese.it).

—, La dinamica processuale nel M.P. «Mitis Iudex», Ius Ecclesiae 28 (2016) 39-61.

Morán Bustos, C. M., El proceso «brevior» ante el Obispo diocesano: requisitos procesales y sustantivos de un proceso que ha de ser extraordinario, RGDCDEE 41 (mayo 2016) 1-52.

-, Retos de la reforma procesal de la nulidad del matrimonio, Ius Canonicum 56 (2016) 9-40.

NaPOLITANO, E., Il processus brevior nella Lettera Apostolica motu proprio datae Mitis Iudex Dominus Iesus, Monitor Ecclesiasticus CXXX (2015) 549566.

Ortiz, M. Á., La forza probatoria delle dichiarazioni delle parti nelle cause di nullità di matrimonio, en H. FRANCESCHI - M. Á. ORTIZ (cur.), Verità del consenso e capacità di donazione, Edusc, Roma 2009, 387-449.

-, Le dichiarazioni delle parti e la prudente valutazione della loro forza probatoria, en H. FranCESCHI - M. Á. ORTIZ (cur.), Ius et matrimonium II. Temi processuali e sostanziali alla luce del Motu Proprio Mitis Iudex Dominus Iesus, Edusc, Roma 2017, 219-277. 
OTADUY, JAVIER, El principo de jerarquía normativa y la Instrucción Dignitas connubii, Ius Canonicum 46 (2006) 59-97.

PEÑa, C., Matrimonio y causas de nulidad en el derecho de la Iglesia, Universidad Pontificia Comillas, Madrid 2014, 503 pp.

-, El nuevo proceso «breviore coram episcopo» para la declaración de la nulidad matrimonial, Monitor Eclesiasticus CXXX (2015) 567-593.

PompedDa, M. F., Studi di diritto processuale canonico, Giuffrè, Milano 1995, 289 pp.

RIPA, A., La novità mancata, Lateran University Press, Città del Vaticano 2010, $262 \mathrm{pp}$.

RodrígueZ-OcaÑa, R., Addenda. Nuevos cánones sobre procesos de declaración de nulidad de matrimonio con sus comentarios actualizados, AA. Vv., Código de Derecho Canónico. Edición anotada, Eunsa, Pamplona 2016.

SERRANO Rutz, J. M., Confessione e dichiarazione delle parti nella giurisprudenza della Rota, en S. GHERRO (cur.), Confessione e dichiarazione delle parti nelle cause canoniche di nullità matrimoniale, CEDAM, Padova 2003, 147-170.

Toxé, P., La réforme des procés en nullité de mariage en Droit canonique latin selon le motu proprio Mitis Iudex Dominus Iesus, en C. Dounot - F. Dussaubat (dirs.), La réforme des procédures des nullités de mariage. Un étude critique, Artège Lethielleux, Paris 2016, 247 pp.

Tribunale Apostolico della Rota Romana, Sussidio applicativo del Motu pr. Mitis Iudex Dominus Iesus, Città del Vaticano, gennaio 2016, 72 pp.

Zambon, A., Il motu proprio Mitis Iudex Dominus Iesus. Prima presentazione. Testo aggiornato al 9 novembre 2015, http://www.ascait.org/sites/default/files/MID_Presentazione_2015-11-09\%20(1).pdf.

ZuanazZI, G., Psicologia e psichiatria nelle cause matrimoniali canoniche, LEV, Città del Vaticano 2006, 384 pp. 
